\title{
Non-covalent Functionalization of Graphene to Tune Its Band Gap and Stabilize Metal Nanoparticles on Its Surface
}

\author{
Paloma Arranz-Mascarós,* Maria Luz Godino-Salido, Rafael López-Garzón, Celeste García-Gallarín, \\ Ignacio Chamorro-Mena, F. Javier López-Garzón, Esperanza Fernández-García, \\ and María Dolores Gutiérrez-Valero
}

Cite This: ACS Omega 2020, 5, 18849-18861

Read Online

\begin{abstract}
ACCESS 1
Llll Metrics \& More

Article Recommendations

Supporting Information

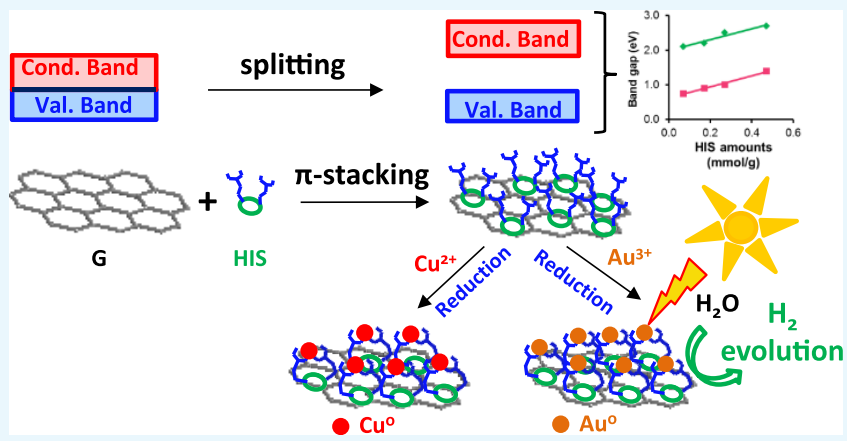

ABSTRACT: Controlling graphene conductivity is crucial for its potential applications. With this focus, this paper shows the effect of the non-covalent bonding of a pyrimidine derivative (HIS) on the electronic properties of graphene (G). Several G-HIS hybrids are prepared through mild treatments keeping unaltered the structures of both G and HIS. The attachment of HIS to G occurs by $\pi-\pi$ stacking of the HIS-aromatic residue with the G surface. This partially blocks the $\mathrm{p}_{z}$ electrons of G, giving rise to the splitting of both the valence and conduction bands. Moreover, the width of the splitting is directly related to the HIS content. This fact allows the fine-tuning of the band gap of G-HIS hybrids. Furthermore, HIS keeps its metal-complexing ability in the G-HIS hybrids. Taking advantage of this, a G-HIS- $\mathrm{Cu}(0)$ composite was prepared by $\mathrm{H}_{2}$ plasma reduction of a precursor of the G-HIS-Cu(II) type. GHIS- $\mathrm{Cu}(0)$ contains $\mathrm{Cu}(0)$ clusters stabilized on the $\mathrm{G}$ surface due to interactions with the $\mathrm{COO}^{-}$functions of $\mathrm{HIS}$. In an analogous hybrid, G-HIS- $\mathrm{Au}(0)$, the $\mathrm{Au}(0) \mathrm{NPs}$ are also stabilized by $\mathrm{COO}^{-}$functions. This material, consisting of the coupling of $\mathrm{Au}(0) \mathrm{NPs}$ and G-HIS, photocatalyzed water reduction under visible light radiation producing $12.5 \mu \mathrm{mol} \cdot \mathrm{g}^{-1} \cdot \mathrm{h}^{-1} \mathrm{of}$ hydrogen.
\end{abstract}

\section{INTRODUCTION}

Graphene is a strong material that is mechanically flexible and transparent with very high electrical and thermal conductivity and a large surface area. ${ }^{1-4}$ Due to these properties, it has received a great deal of attention in many different fields of science and engineering. Nevertheless, depending on every particular case, certain intrinsic obstacles make application of pristine graphene difficult, which causes chemical/structural changes that can be carried out in different ways necessary. For example, oxidized graphene, GO, and heteroatom moleculefunctionalized graphene (modified graphene-based materials) coupled to photocatalysts have been used to improve the efficiency of different kinds of photocatalytic reactions. ${ }^{5,6}$ One of these reactions is the photocatalytic reduction of water for hydrogen production. Developing suitable photocatalysts for this reaction by using light as an activating source is receiving increasing attention as part of the response to the challenge of providing for the energy demands without causing environmental pollution by fossil fuel consumption. To this purpose, coupling of GO or heteroatom-modified graphene with semiconductor NPs of different natures has been used as a procedure to obtain composites that behave as efficient photocatalysts in water reduction. In these materials, the efficiency comes from the synergistic functioning of the components of the photocatalyst. The graphene moieties act as a cocatalyst receiving the electrons excited in the semiconductor by visible light, which are then used in the photoreduction process. In this point, the high dispersibility of GO in water and the high surface area of the graphene moieties that allows wide spreading of the excited electrons (avoiding electron-hole recombination in the catalysts) thus increasing

Received: April 30, 2020

Accepted: July 7, 2020

Published: July 22, 2020 
the active reduction sites are key factors in the improvement of G-based photocatalysts in hydrogen production. Moreover, the semiconducting character of GO or heteroatom-functionalized $\mathrm{G}$ and the ability of the $\mathrm{sp}^{2}$ domains to interact with $\mathrm{H}_{3} \mathrm{O}^{+}$, acting as activating factors for the reduction reaction, are also key factors in the high performance of these photocatalysts. ${ }^{7,8}$

GO can be considered as a $\mathrm{G}$ derivative bearing hydrophilic oxygen functions that make it easily dispersible in water. These functions are associated to defects and holes in the sheets of $\mathrm{GO}$, which disrupt the uniform sequence of $\mathrm{C} \mathrm{sp^{2 }}$ atoms, which results in the separation of the valence and conduction bands (VB and $\mathrm{CB}$ ) of these domains by an energy band gap. As a consequence, the band gap of GO increases as the oxidation degree rises; ${ }^{10,11}$ thus, the electronic conductivity of graphene can be tuned through suitable control of its oxidation. ${ }^{12}$ A major drawback on using GO for developing coupled GO semiconductors is the inherent damage of the $\mathrm{C} \pi$ structure of $\mathrm{G}$ during the oxidizing treatment, which reduces the number of reduction active sites (see above). In addition, the high temperatures and hard chemical treatment used during the oxidizing process bear intrinsic difficulty in tuning the band gap of the resulting material.

Contrary to the modified graphene derivatives, GO, and heteroatom-modified graphene, using untreated graphene coupled with semiconductors for photocatalytic water reduction reactions has two important limitations. On the one hand, the low dispersibility of graphene, G, in water due to the low structural polarity and, on the other, the lack of a semiconductor character with CBs of suitable energy for the electrons transferred from the coupled light-absorbent NPs reduce water.

Nevertheless, exploring possible ways to overcome these drawbacks is important because the use of unmodified graphene in photocatalysis has two important advantages: (i) preservation of its aromatic structure, which ensures that it will provide high amount of $\mathrm{C} \pi$ centers, and (ii) avoiding the use of harsh conditions required for oxidizing or obtaining heteroatom graphene derivatives. In this work, we have explored non-covalent functionalization of graphene with very low oxygen content with a molecular pyrimidine compound in view of its further use as support of lightabsorbent metal NPs as potential active photocatalyts in water reduction.

We have previously reported that the attachment of $\mathrm{C}(5)$ nitroso-pyrimidine derivatives (Scheme 1a) onto the

Scheme 1. Structure of (a) C(5)nitroso-pyrimidine derivatives and (b) HIS.
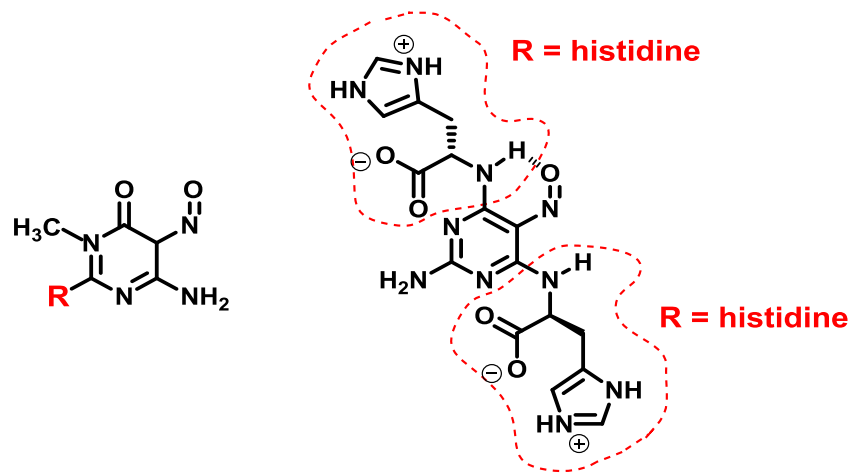

a surface of some carbon materials takes place by $\pi$ stacking between the planar pyrimidine-conjugate residue and the arene centers, $\mathrm{C} \pi$, of the graphene surface. ${ }^{13-18}$ This interaction is driven not only by van der Waals forces but also by a strong polar interaction, ${ }^{19}$ arising from the electron-withdrawing $\pi$ cloud by the exocyclic $\mathrm{C}(5)-\mathrm{NO}$ group. $^{20-22}$ Thus, it is expected that this mechanism is preserved when compounds similar to those of Scheme la but with different substituent $\mathrm{R}$ are attached to graphene. This will result in graphenepyrimidine derivative hybrids having on their surface the $R$ function of the pyrimidine derivative. The hypothesis is that this attachment will give rise to the blockage of a part of the $\mathrm{p}_{z}$ orbitals of the graphene surface, which will result in a decrease in the extension of the $\pi$-resonant system of the graphene sheets. This means that the controlled non-covalent attachment of pyrimidine derivatives (Scheme 1a) on graphene can be a suitable strategy to tune the semiconducting character of the graphene sheets. The strategy we propose has two important advantages over graphene oxidation, see above: (i) the attachment takes place in mild conditions (water solution at room temperature), which avoids structural damage of the graphene sheets and allows preservation of the aromatic structure of the sheets; (ii) the procedure also allows strict control of the attached amount, i.e., enables tuning the band gap, which is difficult to do via graphene oxidation.

According to the above, in this work, the effect of the attachment of different amounts of a pyrimidine derivative (HIS, Scheme 1b) to the surface of a few-layered graphene, G, on its optical properties has been studied. Moreover, two composites were prepared and characterized by deposition of $\mathrm{Cu}(0)$ and $\mathrm{Au}(0)$ metal NPs on one of the G-HIS hybrids previously prepared, and we have investigated the possible role of the pyrimidine-pendant functions of HIS (two histidine residues) in the stabilization of both metal ions and metal NPs. ${ }^{18,23,24}$ This has been done by taking G-HIS-Cu(0) composite as model, on the basis of the reactivity of HIS$\mathrm{Cu}(\mathrm{II})$ mixture in water. Finally, preliminary tests were carried out on the photocatalytic activity of G-HIS- $\mathrm{Cu}(0)$ and G$\mathrm{HIS}-\mathrm{Au}(0)$ under solar light radiation in the water reduction reaction, which showed that hybrids of the above type are potentially efficient as photocatalyts.

\section{RESULTS AND DISCUSSION}

Preparation and Characterization of G-HIS Materials. Partial characterization of graphene, G, has been done in a previous publication of the authors. ${ }^{25}$ Additionally, the elemental composition of $\mathrm{G}$ after washing with water, obtained from the survey XPS, was $95.8 \% \mathrm{C}, 0.3 \% \mathrm{~S}$, and $3.9 \% \mathrm{O}$. Deconvolution into the components of $\mathrm{C} 1 \mathrm{~s}$ and $\mathrm{O} 1 \mathrm{~s}$ highresolution XPS spectra was done to get insight into the nature of the oxygen functions. To carry this out, both the corresponding background literature and the accuracy of XPS measurements $( \pm 0.2 \mathrm{eV})$ were taken into account. In Figure 1, the deconvolution of the $\mathrm{C}$ 1s high-resolution XPS spectrum shows the components of the aromatic $\mathrm{sp}^{2} \mathrm{C}$ atoms (at ca. $284.6 \mathrm{eV}$ ), epoxy and hydroxyl groups (at ca. $286.2 \mathrm{eV}$ ), and carbonyl (at $287.3 \mathrm{eV}$ ) and carboxyl functions (at 289.0 $\mathrm{eV})$. Deconvolution of the $\mathrm{O} 1 \mathrm{~s}$ high resolution spectrum (Figure 2) allows quantitative determination indicating that the oxygen amount as epoxy and hydroxyl groups is $65.1 \%$, as carbonyl functions, $27.8 \%$, and as carboxylic functions, $7.1 \%{ }^{26,27}$ In a previous paper, ${ }^{28}$ a value of $I_{\mathrm{D}} / I_{\mathrm{G}}=1.02$ for the relationship between the intensities of $D$ and $G$ bands at 


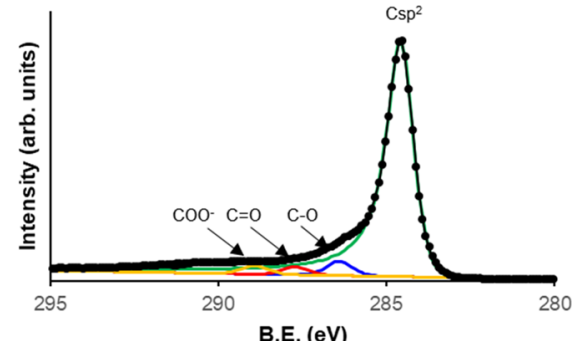

Figure 1. High-resolution XPS spectrum of G in the C 1 s region. ${ }^{25}$

1336 and $1585 \mathrm{~cm}^{-1}$ in the Raman spectra was reported for G, which is in accordance with very low oxygen content. Although this value is not conclusive about the nature of the $G$ material used in this work, the low $I_{\mathrm{D}} / I_{\mathrm{G}}$ value, together with the very low oxygen content and the fact that almost the whole $\mathrm{C} 1 \mathrm{~s}$ signal corresponds to hybridized $\mathrm{C} \mathrm{sp} \mathrm{s}^{2}$, points out that $\mathrm{G}$ is a few-layered graphene material. However, a relatively large intensity of the D band suggests a significant amount of irregularities and defects. This should be explained by the little sizes of the layers of $\mathrm{G}$ sheets (see the Experimental Section) in which the defects should be placed at the edges thus being relatively significant compared to the sizes. ${ }^{29}$ Thus, according to all these data, $G$ could be considered as a few-layered graphene with low oxygen content.

The non-covalent attachment of HIS on G was studied as a previous step to obtain G-HIS dispersible hybrid materials.
Thus, the HIS water retention isotherm on G was obtained (Figure S1). This isotherm fits the $\mathrm{H}$ type of Giles's classification, $^{30}$ which is consistent with a plane-to-plane interaction of the arenic centers on the surface of $G$ with the aromatic pyrimidine residue of HIS. ${ }^{17,18,24}$ According to the literature, the Langmuir isotherms showing $\mathrm{H}$ shapes indicate high affinity between the adsorbent and the adsorbate. ${ }^{30}$ This is also consistent with the low desorption values found for HIS from the G-HIS hybrid, which range from $0 \%$ at minimum HIS coverage to ca. $11 \%$ at the maximum (Figure S1). On the basis of this study and following methodology described in the Experimental Section, we have obtained four G-HIS hybrids labeled as G-HIS(0.47), G-HIS(0.27), G-HIS(0.17), and GHIS(0.07) containing $0.47,0.27,0.17$, and $0.07 \mathrm{mmol}$ of HIS per gram of $\mathrm{G}$, respectively.

Additional evidence of the strong interaction of HIS with the $\mathrm{G}$ surface was provided by the high-resolution XPS spectra in the $\mathrm{N} 1 \mathrm{~s}$ region of HIS and G-HIS (0.47) (Figure 3). The N 1s spectrum of HIS of Figure 3 is deconvoluted into three components, which are assigned to the C(5)-NO group (396.5 $\mathrm{eV}), \mathrm{N}_{\text {pyrimidine cyclic }}+\mathrm{N}_{\text {[amine]pyrimidine }}$ conjugate $(397.7 \mathrm{eV}$ ) groups, and the four $\mathrm{N}_{\text {imidazole groups }}(399.2 \mathrm{eV})$. Significant differences in the peak positions of the components have been explained previously ${ }^{13}$ because of the polarity of the pyrimidine moiety (in the case of the two former ones). The relative high B.E. of the imidazole atoms is explained by the net positive charge that they bear (Scheme 1). On the other hand, large FWHM values of the components (especially the last
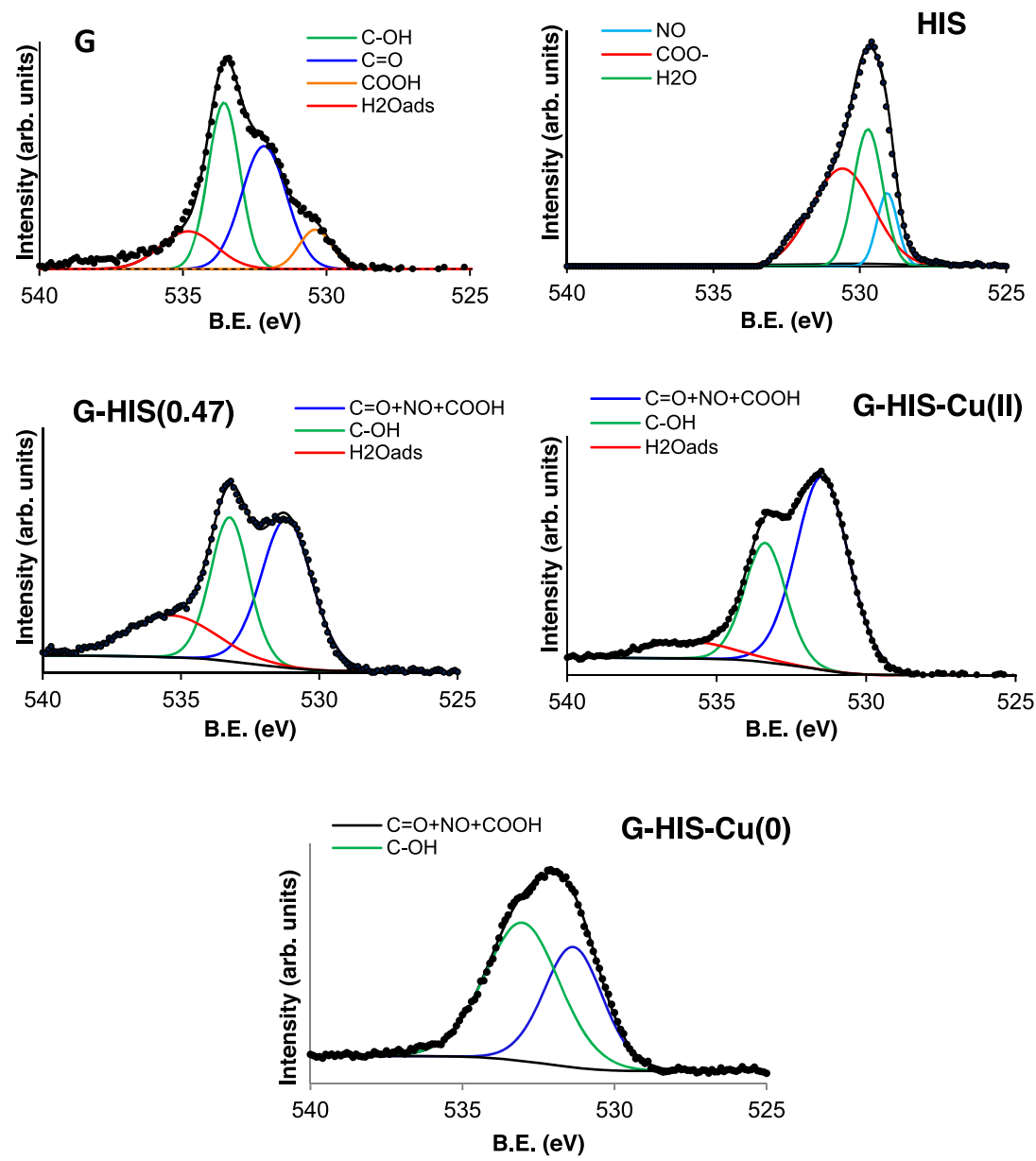

Figure 2. High-resolution XPS spectra in the O 1s region of G, HIS, G-HIS(0.47), G-HIS-Cu(II), and G-HIS-Cu(0). 

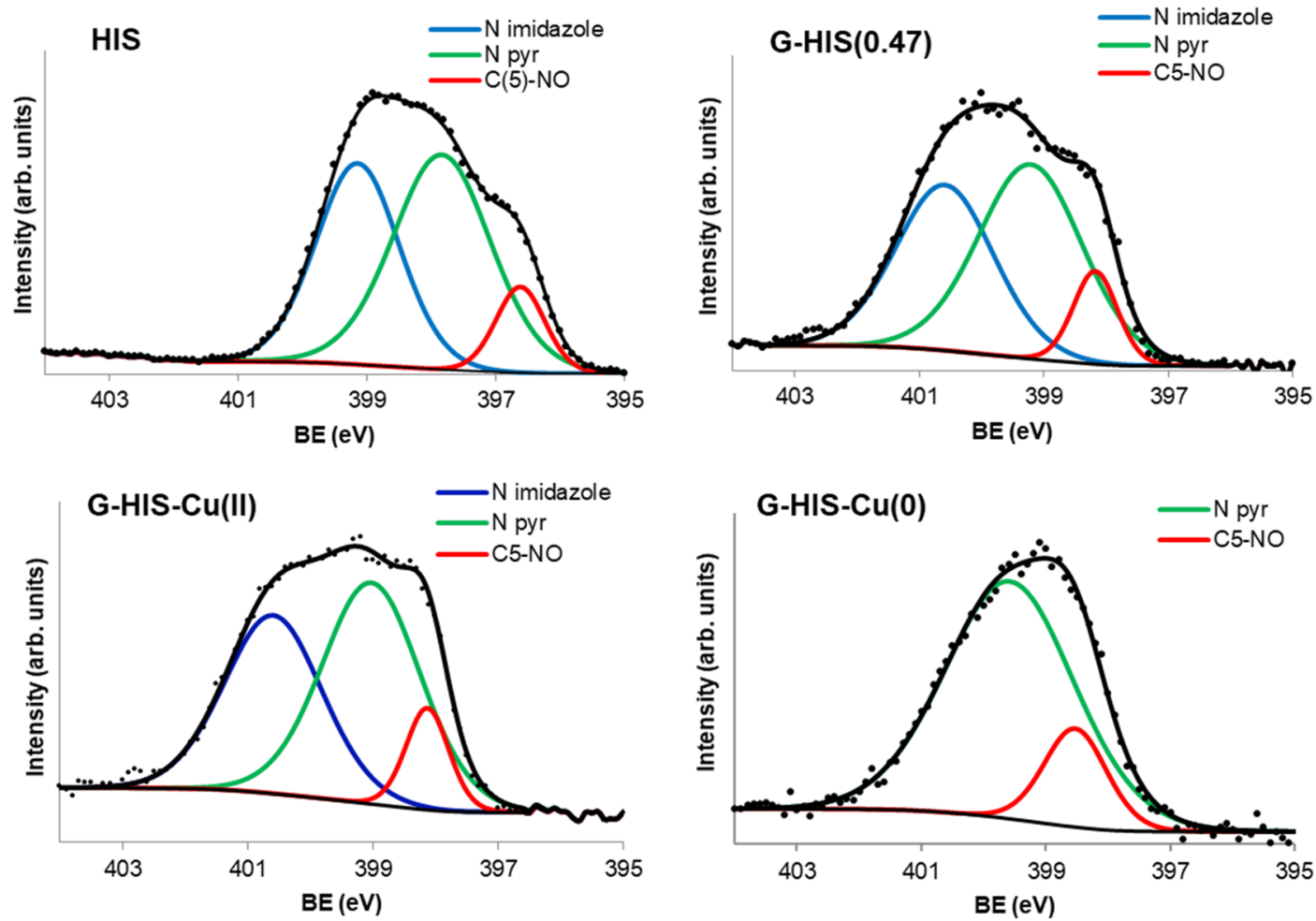

Figure 3. High-resolution XPS spectra in the $\mathrm{N}$ 1s region of HIS, G-HIS(0.47), G-HIS-Cu(II), and G-HIS-Cu(0).

two) is explained because each of the component encompasses several nitrogen atoms with different, although slightly, structural environments (Scheme 1). The components in the G-HIS(0.47) spectrum of the conjugate $\mathrm{C}(5)-\mathrm{NO}$ group $(398.1 \mathrm{eV})$ and those assigned to the $\mathrm{N}_{\text {pyrimidine cyclic }}+$ $\mathrm{N}_{\text {[amine]pyrimidine }}$ conjugate $(399.1 \mathrm{eV})$ appear at higher binding energy values than in the pure HIS (396.5 and $397.7 \mathrm{eV}$, respectively). Interactions with graphene-like surfaces of the pyrimidine moieties of similar ligands that give rise to shifting toward higher B.E. values of ring and conjugate nitrogen atoms have been previously described as the result of $\pi-\pi$ stacking of the pyrimidine plane with the $\mathrm{C} \pi$ ones (pyrimidine-C $\pi$ interactions). This occurs because the interacting planar moieties are compressed one on the other giving rise to local repulsion of the adjoined $\pi$ clouds, which causes deshielding of the $\mathrm{N}$ pyrimidine atoms. ${ }^{13,14,18}$ The component of both imidazole moieties appears also shifted to a higher B.E. value $(400.5 \mathrm{eV})$ than in the HIS. This fact, which was observed with a similar ligand bearing conjugated moieties attached to the pyrimidine plane, ${ }^{18}$ has been rationalized in terms of different conformations of the ligand with respect to the solution. Analyses carried out demonstrated that an elongated arrangement of the adsorbed pyrimidine is required to optimize the stacking interactions with the $G$ surface, which could give rise to the observed shifting. Nevertheless, such an interaction in this case does not affect significantly the acid-base behavior of the imidazole moiety as shown in the data of Table 1 . The XPS spectrum of G-HIS in the O 1s region shows similar behavior of the signal of the $\mathrm{C}(5)$-NO group of the pyrimidine moiety, which is widely shifted in the G-HIS $(0.47)$ spectrum to higher B.E. values than in the HIS one (see Figure 2). Worth mentioning is the significant amount of water retained by this composite, which is attributed to both the hydrophilicity of the
Table 1. Theoretical $\mathrm{pK}$. Values of the Acidic Functions of G and G-HIS(0.47) Surfaces

\begin{tabular}{lllll}
\multicolumn{2}{c}{$\mathrm{G}$} & & \multicolumn{1}{c}{$\mathrm{G}-\mathrm{HIS}(0.47)$} \\
\cline { 1 - 1 } $\mathrm{pK}_{\mathrm{a}}$ & \multicolumn{1}{c}{ group } & & $\mathrm{p} K_{\mathrm{a}}$ & \multicolumn{1}{c}{ group } \\
2.6 & $-\mathrm{COOH}$ & & 2.6 & $-\mathrm{COOH}(\mathrm{G}, \mathrm{HIS})$ \\
4.7 & $-\mathrm{COOH}$ (anhyd.) & & 4.2 & $-\mathrm{COOH}$ (anhyd.) \\
7.8 & $\mathrm{C} \pi-\mathrm{H}_{3} \mathrm{O}^{+}$ & & 5.9 & $\mathrm{~N}_{\text {cyclic imidazole }}$ \\
9.3 & $\mathrm{C}-\mathrm{OH}$ & 8.7 & $\mathrm{C} \pi-\mathrm{H}_{3} \mathrm{O}^{+}, \mathrm{C}-\mathrm{OH}, \mathrm{C}(4)_{\mathrm{pyr}}-\mathrm{NH}_{2}$ \\
& & &
\end{tabular}

polar groups of HIS together with the retaining of $\mathrm{H}_{3} \mathrm{O}^{+}$ions on the $\mathrm{C} \pi$ centers of the $\mathrm{G}$ surface.

The proton isotherms of G and G-HIS(0.47) (Figure 4) provide information on the way the attachment of HIS onto the $G$ surface affects the acid-base properties of G. It is expected that the surface charge of the hybrid is different from the precursor material, G. With the aim of checking this fact, we have carried out measurements of the isoelectric point of $G$

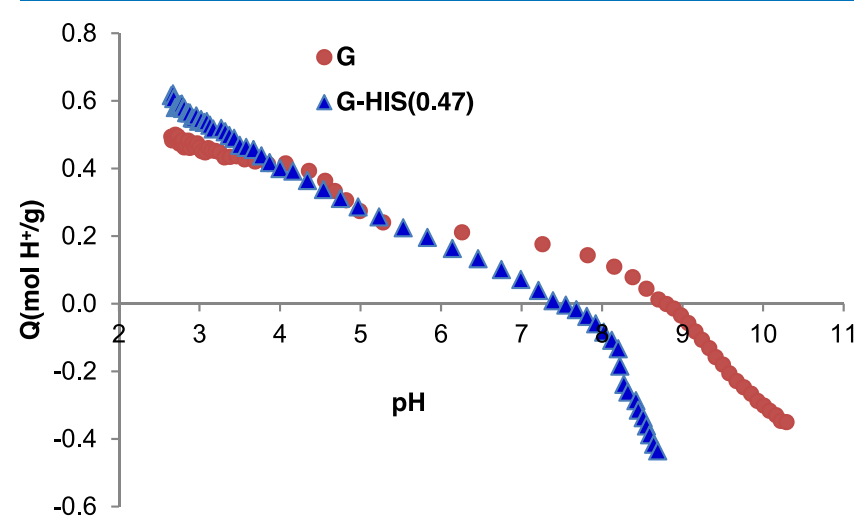

Figure 4. Proton isotherms of G and G-HIS(0.47). 
bare and the hybrid G-HIS $(0.47)$. It is seen that G has a basic isoelectric point (8.6) due to the arenic centers, $\mathrm{C} \pi$. Nevertheless, the value of this point decreases (7.2) in the hybrid due to the presence of the carboxylic acids and the protonated imidazole residues from HIS. The plots also support the fact that the acid-base properties of HIS have been transferred to the hybrid. An outcome of this transfer is that the hybrid is water-dispersible. The surface charge profile of G and G-HIS (0.47) is discussed in detail in the Supporting Information. Moreover, the numerical SAIEUS procedure ${ }^{31,32}$ was applied to the proton isotherms of G and G-HIS $(0.47)$ (Figure S6b) to determine the theoretical $\mathrm{p} K_{\mathrm{a}}$ values of the acidic surface functions (Table 1 ).

Tuning of the Band Gap of $\mathrm{G}$ by Attachment of HIS. The effect of the attachment of HIS on the electronic properties of $\mathrm{G}$ was analyzed by comparing the electronic spectra (Figure 5) of G-HIS(0.47), G-HIS(0.27), GHIS (0.17), and G-HIS(0.07).

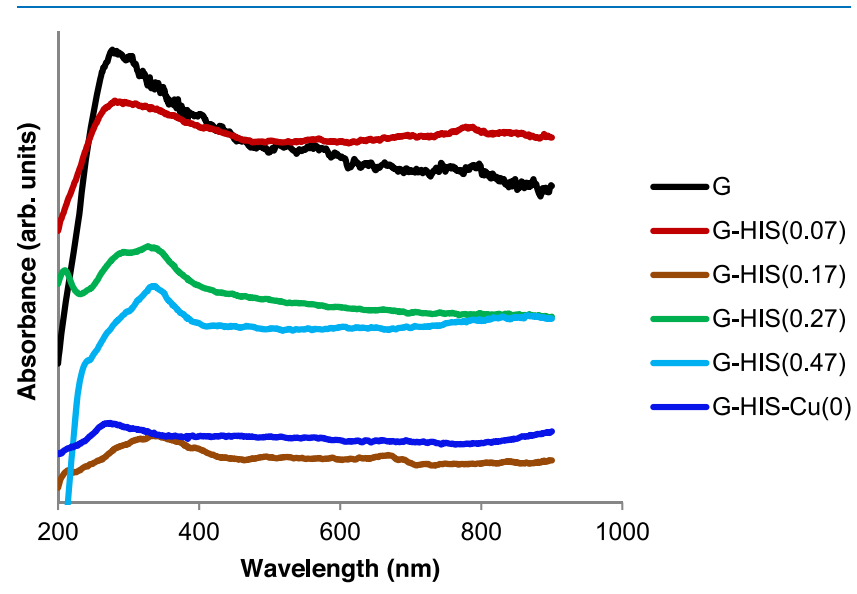

Figure 5. UV-vis absorption spectra of G, G-HIS hybrids, and G$\mathrm{HIS}-\mathrm{Cu}(0)$.

The UV spectrum of G shows an asymmetric band with a maximum at ca. $280 \mathrm{~nm}$. According to the literature, this maximum is assigned to $\pi-\pi^{*}$ plasmon transitions from the $\mathrm{sp}^{2}$ domains of $\mathrm{G}$. Moreover, the wavelength of this maximum is characteristic of few-layered graphene (1-3 layers). The asymmetry is probably due to $n-\pi^{*}$ transitions (which usually appear at higher wavelength, ca. $310-320 \mathrm{~nm}$ ) of non-bonding electrons of the oxygen atoms of conjugate $\mathrm{C}=\mathrm{O}$ and $\mathrm{C}-\mathrm{O}$ functions. $^{11,33,34}$ The UV-visible spectra of the water dispersions of hybrids (Figure 5) show broad absorptions in the UV range resulting from the overlap of the absorption maxima of HIS (Figure S7) with those of G. Moreover, the spectra of the hybrids in the whole visible range clearly show increased absorption compared to G. Comparison of the valence band $(\mathrm{VB})$ region in the high-resolution XPS spectra of $\mathrm{G}$ and G-HIS provide further evidence that the attachment of HIS to the G surface does alter the electronic properties of the former. Therefore, in the range of the electrons of the $\pi$ orbitals of G (up to $10 \mathrm{eV}$, see Figure 6), there appears a plateau in the G-HIS $(0.47)$ spectrum between 12.5 and 15.0 $\mathrm{eV}$, which is absent in the bare G. The XPS spectrum in the VB range of the $0.8 \mathrm{mg}$ sample containing only HIS (the amount of HIS present in the G-HIS(0.47)) used to obtain its XPS spectrum did not shown any intensity. Thus, the appearance of the above plateau point out a discontinuous ejection of $\pi$

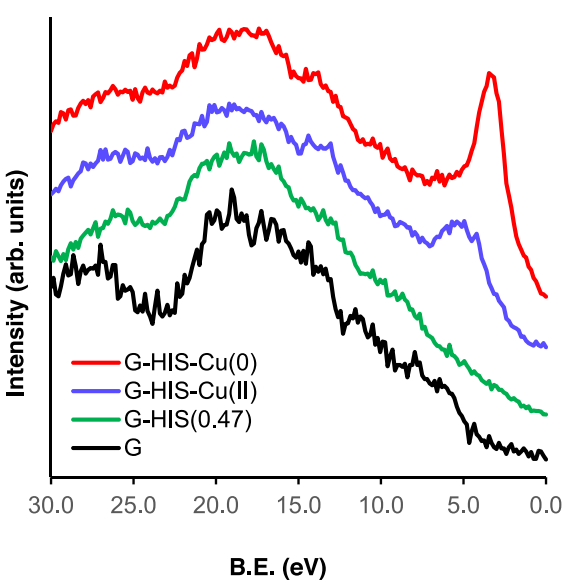

Figure 6. XPS spectra of the valence band for G, G-HIS (0.47), G$\mathrm{HIS}-\mathrm{Cu}(\mathrm{II})$, and G-HIS-Cu(0).

electrons of G in G-HIS $(0.47)$, suggesting that the $\mathrm{C} \pi-\pi_{\mathrm{Pyr}}$ interaction split the overlapped $\pi$ bonding and antibonding orbitals. $^{35}$

To get more insight into the above effect, the UV-visible data have been plotted as the square and square root of the absorption energy ( $\alpha \mathrm{E}$ where $\alpha=$ absorbance) versus the photon energy (Tauc plots) in order to obtain the energies of the direct and indirect transitions, respectively (Figure 7 and

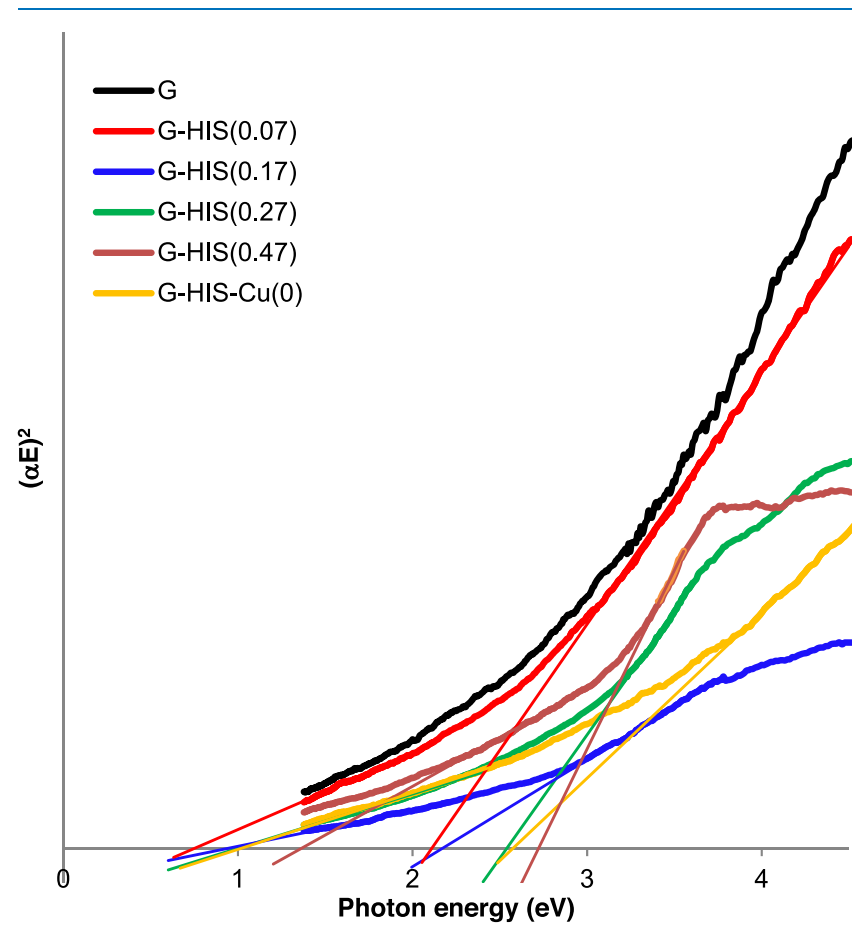

Figure 7. Plots of $(\alpha \mathrm{E})^{2}$ (direct transitions) against the photon energy (E) for G, G-HIS hybrids, and G-HIS-Cu(0).

Figure S8). ${ }^{9,36-38}$ Although the plots of $(\alpha \mathrm{E})^{2}$ against the photon energies $(h v)$ (Figure 7 ) do not show sharp absorption edges, probably because of the non-uniform sizes of the components of the G-HIS hybrids (due to different sizes of the $\mathrm{G}$ sheets), all the hybrids exhibit well-defined edges. This points out the absorption due to direct transitions in the visible range. The linear extrapolation of the edges renders energies for these transitions ranging from $2.8-1.4 \mathrm{eV}$ for the hybrid 
having the highest HIS content (G-HIS $(0.47)$ ) to $2.1-0.8 \mathrm{eV}$ for G-HIS(0.07), the one having the lowest HIS content (Figure 7). It is important to take into account that HIS does not show any absorption due to direct transitions in the visible range. Therefore, these extrapolated values can be undoubtedly assigned to $\pi-\pi^{*}$ allowed transitions between the valence and conduction bands of the functionalized $\mathrm{G}$ sheets. This implies that the strong $\pi-\pi$ interaction of $\mathrm{G}$ rings with the pyrimidine moieties of HIS in G-HIS hybrids ${ }^{13-15,19,39}$ causes the splitting of the overlapped valence and conduction bands of $G$ as a result of the blockage of the $\mathrm{p}_{z}$ electrons of $\mathrm{G}$. This results in the formation of isolated $\mathrm{sp}^{2}$ domains with $\mathrm{p}_{z}$ orbitals having free electrons. This effect is similar to that described in the literature when graphene is oxidized. ${ }^{11}$ The existence of welldefined direct transitions in G-HIS materials suggests that the $\mathrm{sp}^{2}$ domains with $\mathrm{p}_{z}$ orbitals having free electrons have uniform extensions and structures. This is accomplished due to the uniform spread of the HIS molecules on the G surface. Thus, the appearance of two different direct transitions in the G-HIS materials (Figure 7) points out the existence of two welldefined $\mathrm{sp}^{2}$ domains with $\mathrm{p}_{z}$ orbitals having their only electrons free (domains placed inside and on the edge of the G-sheets).

In addition, it is shown in Figure 8 that the band gap energies of G-HIS(0.47), G-HIS(0.27), G-HIS(0.17), and G-

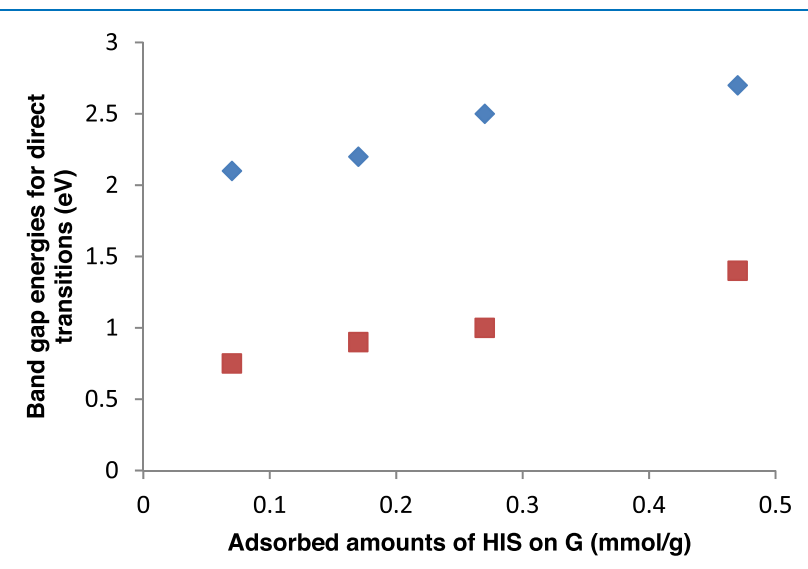

Figure 8. Variation of the semiconducting character of G-HIS hybrids as a function of the adsorbed amounts of HIS.

HIS (0.07) increase with the attached amount of HIS. This is consistent with the above hypothesis that the band gap increasing is related with amount of $\mathrm{p}_{z}$ orbitals blocked on the graphene sheets, i.e., with the amount of HIS attached to the G surface. It is important to note that, in this case, the plot in Figure 8 allows knowing the amount of HIS needed to be attached to $G$ to obtain a hybrid material with a tuned band gap. Nevertheless, given that $\mathrm{G}$ is not composed of molecules of similar sizes and compositions, it should not be expected despite the hypothesis that the correlation of the data obtained is a straight line. On the other hand, it is not easy to explain the origin of the two direct transitions observed in Figure 7 for each of the hybrids, which would need additional research. A tentative explanation could be done by getting insight on the hypothesis of the existence of two different $\mathrm{sp}^{2}$ domains at the G-HIS surface, namely, inside and at the borders of G sheets. In summary, preliminary results of this section point out that non-covalent functionalization of graphene is a suitable strategy for tuning the band gap of the semiconductor hybrid obtained by controlling the extension of the functionalization (Scheme 2). Nevertheless, a more in-depth comprehension on the effect of the attachment of the aromatic moiety of the molecular functionalizing compounds (HIS and analogous compounds) on the properties of $\mathrm{G}$ (i.e., on the conductivity) will require further research.

Preparation and Characterization of G-HIS-Cu(II), GHIS-Cu(0), and G-HIS-Au(0) Materials. As already commented, another important goal driving this work was getting insight into the complexing ability of the histidine residues of HIS adsorbed on G (G-HIS hybrids) to metal ions and atoms (metal NPs). This is an important issue related with the stability of deposited metal species on G-HIS in view of their possible applications. It is known that analogous hybrid materials based on the coupling of various components with semiconductor properties are useful in various applying fields, including those derived from their optical properties. In particular, those systems consisting of GOs with semiconducting properties as one of the components are being the focus of research on their photocatalytic behavior in water reduction. ${ }^{40,41}$

Thus, we have prepared and characterized two $\mathrm{Cu}$ derivatives, G-HIS-Cu(II) and G-HIS-Cu(0), to study the possible stabilizing role of HIS on them. The election of copper as a metal model was driven because the speciation of $\mathrm{Cu}(\mathrm{II})$ in water is well known and the equilibrium times for the species formation are short.

The adsorption isotherm of a water solution of $\mathrm{CuCl}_{2}$ on $\mathrm{G}$ $\mathrm{HIS}(0.47)$ at $298.1 \mathrm{~K}$ and $\mathrm{pH}=5.0$ is shown in Figure S4. A blank experiment showed that the adsorption of $\mathrm{Cu}^{2+}$ on $\mathrm{G}$ was negligible. The isotherm is of the $\mathrm{H}$ type of Giles classification, which points to a single adsorption mechanism. ${ }^{30}$

Scheme 2. Methodology to Obtain Several Graphene-HIS hybrids with Different Optical Properties

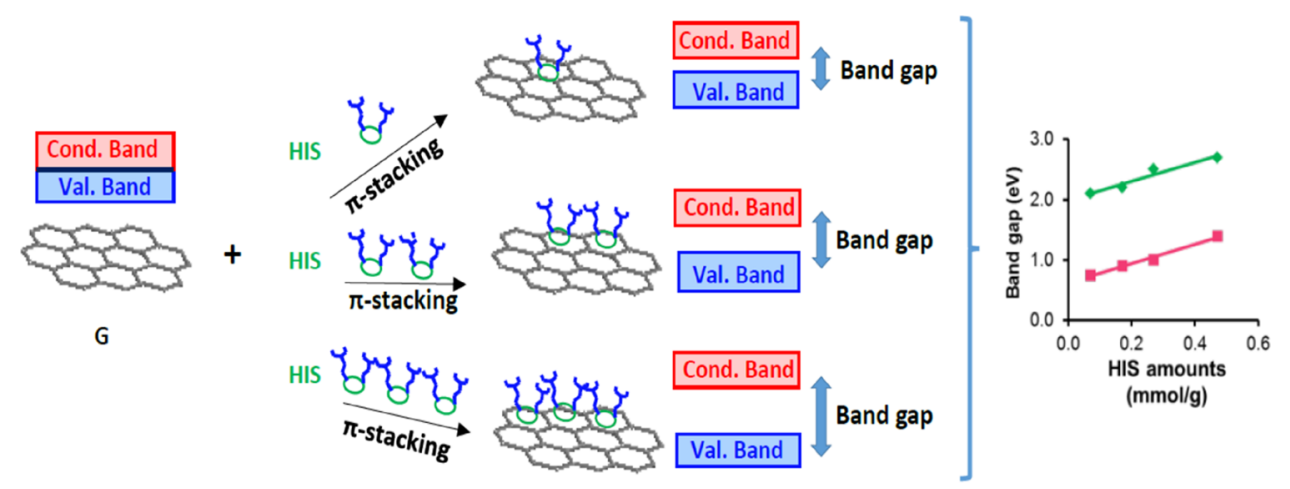


This has been assessed by fitting the experimental data to the Langmuir model $\left(R^{2}=0.9974\right) .{ }^{42,43}$ This allowed us to obtain the value of the maximum adsorption capacity of G-HIS $(0.47)$ for $\mathrm{Cu}^{2+}, X_{\mathrm{mCu}}=0.51 \mathrm{mmol} \cdot \mathrm{g}^{-1}$, which is very close to the molar amount of HIS in the hybrid $\left(0.47 \mathrm{mmol} \cdot \mathrm{g}^{-1}\right)$. This strongly suggests that the attached HIS molecules on GHIS(0.47) play a key role in the retention of $\mathrm{Cu}^{2+}$. To assess this hypothesis, we have studied the reactivity of a $\mathrm{HIS} / \mathrm{CuCl}_{2}$ mixture (1/1 molar relationship) in water solution. The results show that HIS has high ability to form stable complexes with $\mathrm{Cu}^{2+}$ ions with $1 / 1$ metal/ligand stoichiometries (Table S2 and Figure S3). In the $4.5-9.0 \mathrm{pH}$ range, two complex species, $\mathrm{CuHL}(\log K=7.35)$ and $\left[\mathrm{CuH}_{2} \mathrm{~L}\right]^{+}(\log K=6.69)$, are formed. The stability constant values indicate that the $\mathrm{Cu}^{2+}$ ion is coordinated to HIS through both the $-\mathrm{COO}^{-}$group and the $\mathrm{N}_{\text {imidazole-ring }}$ of the deprotonated imidazole. These results suggest that the capture of $\mathrm{Cu}^{2+}$ by G-HIS $(0.47)$ takes place by complexation of one of the histidine residues of the anchored HIS molecules.

The experimental data of the isotherm of $\mathrm{Cu}^{2+}$ on $\mathrm{G}$ HIS(0.47) allowed us to prepare a G-HIS-Cu(II) material having $0.50 \mathrm{mmol}$ of $\mathrm{Cu}(\mathrm{II})$ per gram of G-HIS. In the $\mathrm{Cu} 2 \mathrm{p}$ range of the high-resolution XPS spectrum of G-HIS-Cu(II) (Figure 9), the presence of a peak at $934.0 \mathrm{eV}$ with a satellite at $944.0 \mathrm{eV}$, corresponding to the release of electrons of the $2 \mathrm{p}_{3 / 2}$ state of $\mathrm{Cu}(\mathrm{II}),{ }^{44}$ and of another one at $955.0 \mathrm{eV}$, assigned to the electrons from $\mathrm{Cu} 2 \mathrm{p}_{1 / 2}$ state, is characteristic of those given in the literature for $\mathrm{a}+2$ oxidation state of $\mathrm{Cu}(\mathrm{II}) .{ }^{44}$ The positions of these signals are similar to those found when $\mathrm{Cu}(\mathrm{II})$ was adsorbed on a MWCNT as support, functionalized with a pyrimidine derivative bearing a macrocyclic $\mathrm{Cu}(\mathrm{II})$ complexing function at the $\mathrm{C}(2)_{\text {pyr }}$ position. ${ }^{24}$ Moreover, the fact that, after reduction of G-HIS-Cu(II) with $\mathrm{H}_{2}$ plasma (giving rise to the formation of $\mathrm{Cu}(0)$ clusters), the above main peaks shifts to lower B.E. values, matches with the $\mathrm{Cu}(0)$ oxidation state (Figure 9) is also consistent with the above assignment.

Furthermore, it is observed in the $\mathrm{O}$ 1s high-resolution spectrum in Figure 2 that the $\mathrm{COO}^{-}$component shifts from $530.9 \mathrm{eV}$ (for G-HIS(0.47)) to $531.4 \mathrm{eV}$ (for G-HIS-Cu(II)). The N 1s signal of G-HIS-Cu(II) also shifts from $400.4 \mathrm{eV}$ for G-HIS $(0.47)$ to $401.1 \mathrm{eV}$ for G-HIS-Cu(II) (Figure 3). These data support the fact that the adsorbed $\mathrm{Cu}^{2+}$ ions are complexed by the $-\mathrm{COO}^{-}$groups of histidine residues and the unprotonated $\mathrm{N}_{\text {imidazole-ring }}$. The increase in the intensity of the $\mathrm{O} 1 \mathrm{~s}$ component at $531.4 \mathrm{eV}$ of G-HIS-Cu(II) compared to this of the G-HIS $(0.47)$ also suggests the existence of water molecules coordinated to $\mathrm{Cu}^{2+}$.

The HRTEM image of the pristine graphene only shows some wrinkles and no evidence of other features (Figure S9). ${ }^{28}$ Nevertheless, the reduction of G-HIS-Cu(II) with $\mathrm{H}_{2}$-plasma gives rise to the formation of $\mathrm{Cu}(0)$ nanoparticles uniformly distributed on the G surface as shown in the HRTEM images in Figure 10a. The statistical analysis shows that most of them, ca. $92 \%$, are smaller than $8 \mathrm{~nm}$ with the mean size being ca. 5 $\mathrm{nm}$ (Figure 10b). The $\mathrm{Cu}$ content obtained from the analysis of the XPS spectrum of G-HIS-Cu(0), 0.56 at. \%, is almost equal to that in the unreduced G-HIS-Cu(II), 0.57 at. \%. This means that there is not any lixiviation of $\mathrm{Cu}$ during the reduction process. This fact is probably due to the metal NPs stabilized on the $\mathrm{G}$ surface by the HIS functions.

The high-resolution XPS spectrum of G-HIS-Cu(0) (Figure 9) does not show any of the $\mathrm{Cu}(\mathrm{II})$ peaks. Instead, there are
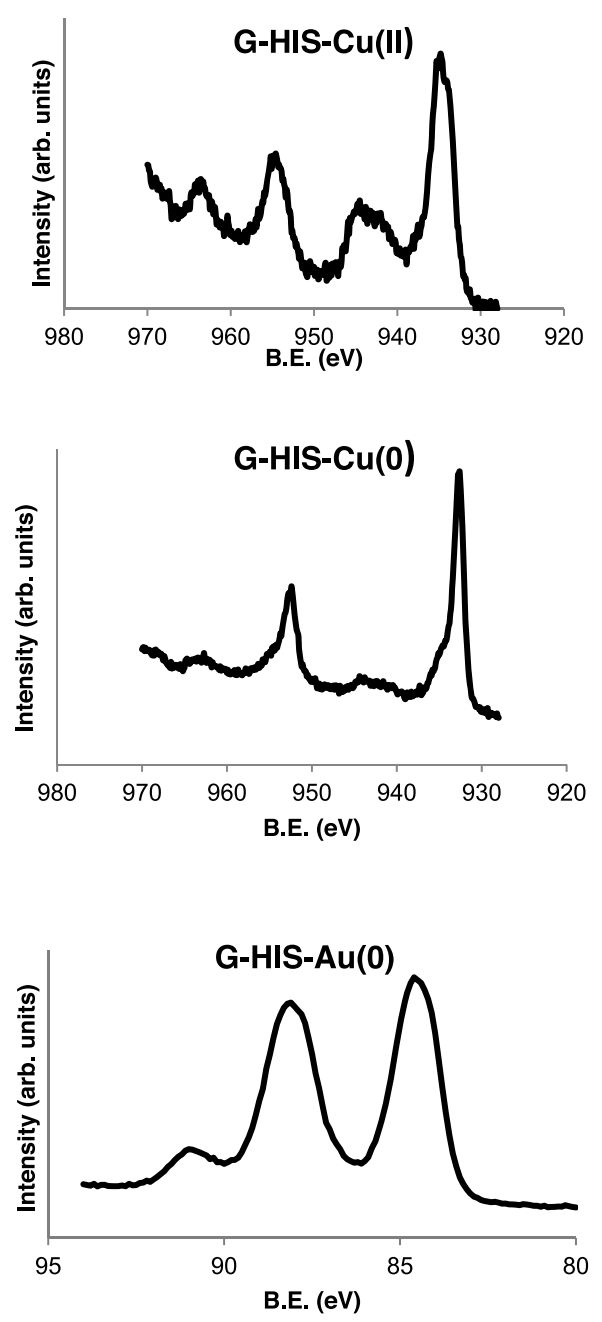

Figure 9. High-resolution XPS spectra in the $\mathrm{Cu} 2 \mathrm{p}$ region of G-HIS$\mathrm{Cu}(\mathrm{II})$ and G-HIS-Cu(0) and $\mathrm{Au} 4 \mathrm{f}$ region of G-HIS-Au(0) (from top to bottom).

two peaks, at $952.5 \mathrm{eV}\left(\mathrm{Cu}(0) 2 \mathrm{p}_{1 / 2}\right)$ and $932.1 \mathrm{eV}(\mathrm{Cu}(0)$ $\left.2 \mathrm{p}_{3 / 2}\right)$, which indicates the quantitative reduction of $\mathrm{Cu}(\mathrm{II})$ to $\mathrm{Cu}(0)$. Moreover, a sharp signal at $3.45 \mathrm{eV}$ (Figure 6) due to the valence band electrons of $\mathrm{Cu}$ NPs and the almost total disappearance of the $\mathrm{Cu}$ (II) band (at ca. $5.1 \mathrm{eV}$ ) also confirm the total reduction of $\mathrm{Cu}$ (II) ${ }^{44}$ It is interesting to note that the reduction with $\mathrm{H}_{2}$ plasma does not significantly affect the oxygen functions of the precursor (see Figure 2). In fact the shape of the high-resolution $\mathrm{O} 1 \mathrm{~s}$ spectra of G-HIS-Cu(0) and G-HIS-Cu(II) and their oxygen content (5.74 and 6.05 at. \%, respectively) are very similar. Moreover, the deconvolution of the $\mathrm{O} 1 \mathrm{~s}$ signal in the G-HIS-Cu(0) spectrum (Figure 2) shows that the $\mathrm{COO}^{-}$component is shifted to a higher binding energy, $531.4 \mathrm{eV}$, than that of the G-HIS $(0.47), 530.9 \mathrm{eV}$. This suggests that these groups interact with the $\mathrm{Cu}(0)$ nanoparticles, which probably contributes to their stabilization in the surface. Nevertheless, a significant decrease of nitrogen of approximately $50 \%$ is observed when G-HIS-Cu(II) is reduced with $\mathrm{H}_{2}$ plasma. This decrease is concomitant with the disappearance of the $\mathrm{N}$ 1s component of the $\mathrm{N}_{\text {imidazole ring }}$ atoms of the protruding imidazole residues (Figure 3). A similar behavior has been systematically observed when metal ions supported on MWCNT functionalized with polyethylenimines were reduced with $\mathrm{H}_{2}$ plasma. ${ }^{45}$ 

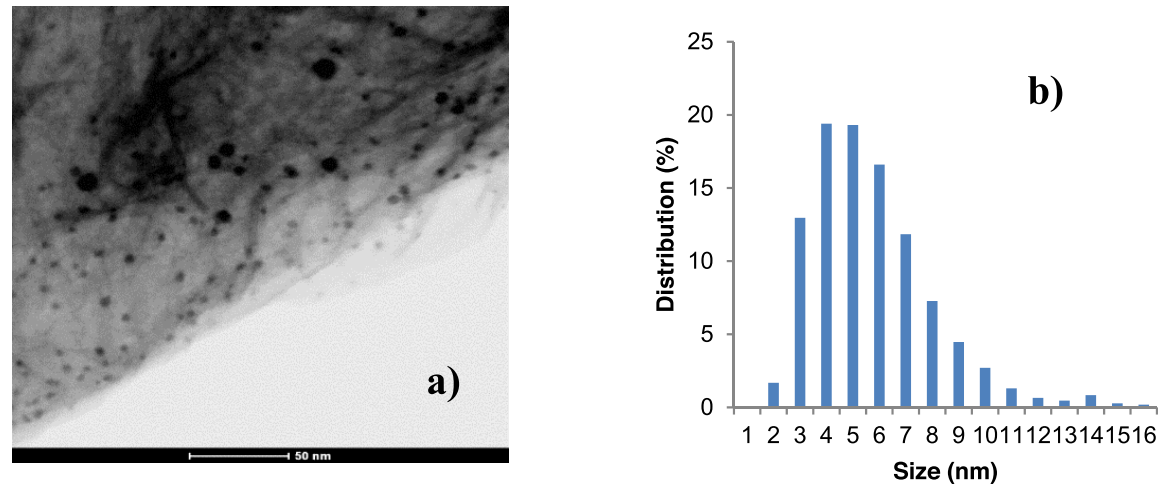

Figure 10. (a) HRTEM image of G-HIS-Cu(0) and (b) particle size distribution of $\mathrm{Cu}(0)$ nanoparticles on its surface.
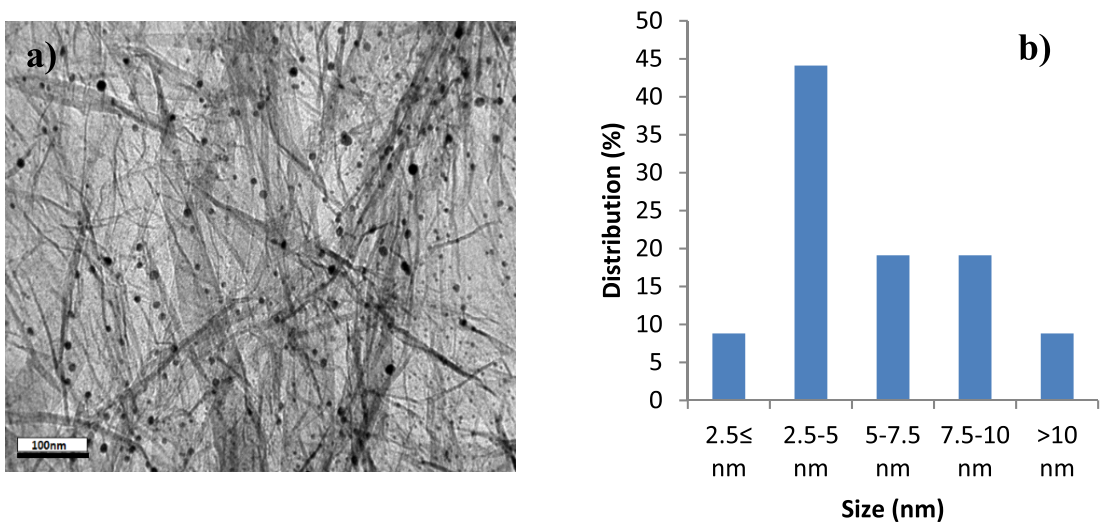

Figure 11. (a) HRTEM image of G-HIS-Au(0) and (b) particle size distribution of $A u(0)$ nanoparticles on its surface.

The UV-visible spectrum of G-HIS-Cu(0) was also obtained to get insight into the influence of the metal NPs on the functionalized graphene. The comparison of the UV spectra of G-HIS-Cu(0), G, and G-HIS(0.47) (Figure 5) shows that, in the former, there is additional absorption at ca. $277 \mathrm{~nm}$, which is assigned to small $\mathrm{Cu}(0)$ clusters with sizes of $<10 \mathrm{~nm}^{46}$ These clusters typically absorb at $\lambda<400 \mathrm{~nm}$ depending on the charge and geometry of the cluster constituents. ${ }^{47}$ As already commented, these types of clusters are predominant in G-HIS-Cu(0) according to TEM analyses (see Figure 10). Moreover, the lack of any absorption band at ca. $550 \mathrm{~nm}$, which is characteristic of plasmon resonance of larger $\mathrm{Cu}(0)$ nanoparticles, ${ }^{47,48}$ is also consistent with the results from TEM analysis, which show a unimodal distribution of particles of 3-10 nm in size.

The plot of $(\alpha \mathrm{E})^{2}$ against the photon energy (E) (Tauc representation) for the determination of the band gap of GHIS- $\mathrm{Cu}(0)$ is shown in Figure 7. The linear extrapolation of the plot rendered values of ca. 2.6 and $1.0 \mathrm{eV}$ for the direct transitions (Figure 7). These values are smaller than those of the precursor G-HIS $(0.47)$ hybrid $(2.8$ and $1.4 \mathrm{eV})$. A suitable explanation of the decrease of the energy values upon $\mathrm{Cu}(0)$ deposition is not easy, although it is plausible to think that it could be a consequence of the interaction of $\mathrm{Cu}(0)$ nanoparticles with the surface of G. Interestingly, this explanation points out to some interfacial charge transfer between the metal and the graphene surface.

Photocatalytic Water Tests in Hydrogen Production. In the Introduction section, the photocatalytic activity of the coupled GO-metal NPs in hydrogen production under visible light radiation was emphasized. This comes from the optical interaction of GO and metal NP moieties. In view of the similarity of G-HIS-Cu(0) to these materials and the absorption energy of $\mathrm{Cu}(0)$ in G-HIS- $\mathrm{Cu}(0)$ being high enough (see above section) to promote electron/positive hole formation in G-HIS (0.47) under light radiation, the photocatalytic activities of G-HIS-Cu(0), GHIS $(0.47)$, and $\mathrm{Cu}(0)$ in hydrogen production from water reduction under radiation similar to solar light have been compared with lactic acid as a sacrificial agent. Thus, oxygen generation was not tested in this study. Under the experimental conditions (see the Experimental Section) neither G-HIS $(0.47)$ nor $\mathrm{Cu}(0)$ showed any hydrogen evolution. The lack of photocatalytic activity of GHIS $(0.47)$ is probably due to fast recombination of the electron-hole pairs generated in this material by radiation. When G-HIS- $\mathrm{Cu}(0)$ was used in the catalytic test, $\mathrm{H}_{2}$ evolution was neither observed. Analogous materials of the GO-metal NP type, which combine GOs with semiconductor behavior and semiconductors of the metal NP type, behave as efficient photocatalysts in water reduction. ${ }^{49}$ Nevertheless, comparison of G-HIS-Cu(0) with those materials shows that both the small percent in weight of $\mathrm{Cu}(0)$ in G-HIS- $\mathrm{Cu}(0)$ and the low amount of the UV component of the solar light radiation (which is the one needed for photoexcitation of $\mathrm{Cu}(0)$ clusters $)$ are the possible cause of the inefficiency of this material.

To get more insight on this issue, we have extended the photocatalytic test to a G-HIS-Au(0) hybrid, containing $\mathrm{Au}(0)$ NPs, which was prepared by a mild procedure that prevents any damage to the histidine and $\mathrm{G}$ components (see the Experimental Section). This solid contains $2.28 \mathrm{mmol}$ of $\mathrm{Au}(0) /$ gram. It is worth noting that this amount is larger than 

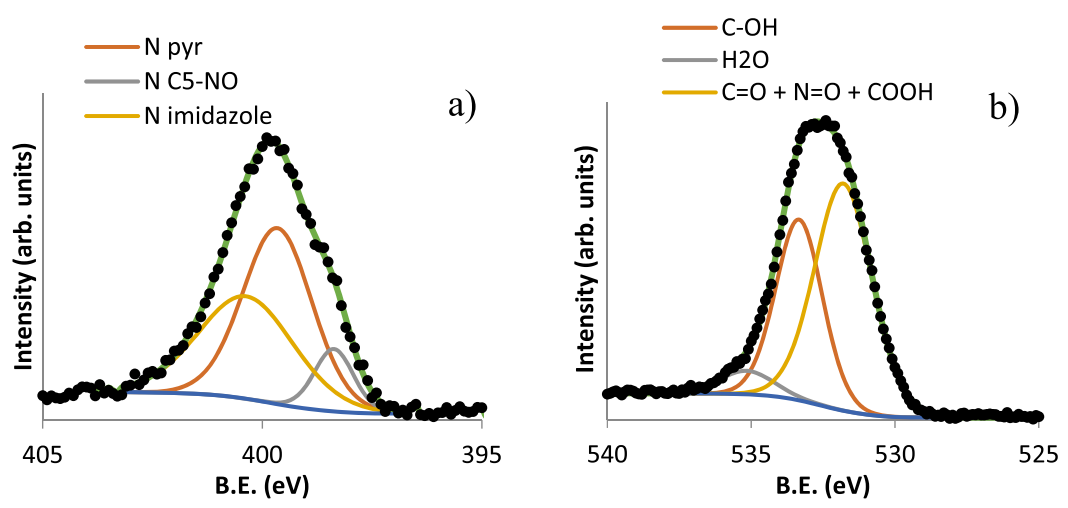

Figure 12. High-resolution XPS spectra in the (a) N 1s and (b) O 1s regions of G-HIS-Au(0).

the histidine content of the hybrid $\left(0.47 \mathrm{mmol} \cdot \mathrm{g}^{-1}\right)$. TEM images (Figure 11) show that small $\mathrm{Au}(0) \mathrm{NPs}$ are extensively and uniformly distributed on the G-HIS $(0.47)$ surface. From the images, it was determined that the mean sizes of $\mathrm{Au}(0)$ NPs range from 2.5 to $10 \mathrm{~nm}$. Although a feasible UV-visible spectrum of the material could not be obtained due to the low water dispersibility, it is expected from the literature data that the $\mathrm{Au}(0) \mathrm{NPs}$ of the hybrid would absorb light at the ca. 500-540 nm range due to surface plasmon resonance (SPR), i.e., with energies between 2.3 and $2.5 \mathrm{eV}$ (ca. 500 to 540 $\mathrm{nm}) .^{50,51}$ The XPS high-resolution spectra can shed light on how the small $\mathrm{Au}(0)$ nanoparticles are stabilized on the surface of the hybrid. Thus, the spectrum of G-HIS-Au(0) in the $\mathrm{Au} 4 \mathrm{f}$ region (Figure 9) shows two peaks at $88.5\left(4 \mathrm{f}_{5 / 2}\right)$ and 84.2 $\left(4 \mathrm{f}_{7 / 2}\right) \mathrm{eV}$, which confirms that most of $\left[\mathrm{AuCl}_{4}\right]^{-}$is reduced to $\mathrm{Au}(0) .{ }^{44}$ The $\mathrm{N} 1 \mathrm{~s}$ component (Figure 12) of the imidazole residue of G-HIS-Au(0) hybrid appears at the same value as that in the case of G-HIS(0.47) (Figure 3). This points out that the nitrogen atoms of the imidazole residues remain protonated and do not interact with the $\mathrm{Au}(0)$ nanoparticles. Nevertheless, the $\mathrm{COO}^{-}$component of the $\mathrm{O}$ 1s signal of G$\mathrm{HIS}-\mathrm{Au}(0)$ is shifted to a higher energy, $531.8 \mathrm{eV}$, than in the case of G-HIS $(0.47)(530.9 \mathrm{eV})$. This fact suggests that the carboxylate functions strongly interact with $\mathrm{Au}(0) \mathrm{NPs}$.

It has been reported that materials consisting of metal NPs having plasmon resonance (SPR) deposited on semiconductors, the electromagnetic field created by SPR, may interact with the surface of the semiconductor. Should the dipole energy created by the oscillation penetrate into the semiconductor through the heterojunction and is high enough relative to the band gap of the semiconductor, the transferred energy can contribute to stabilizing the electron-hole separation created in the semiconductor. ${ }^{52}$ The energy associated to SPR of NPs gives rise to absorption in the UV-visible range and depends on the size of the NPs as the lower the size, the higher the energy.

Differently from G-HIS-Cu(0), when G-HIS-Au(0) was used as a photocatalyst in the same reaction as G-HIS-Cu(0), significant $\mathrm{H}_{2}$ evolution (approximately $12.5 \mu \mathrm{mol} \cdot \mathrm{g}^{-1} \cdot \mathrm{h}^{-1}$ ) was observed $(\mathrm{a} \mathrm{Au}(0)$ sample that precipitated in the absence of G-HIS (0.47) did not show any photocatalytic activity). Compared to G-HIS-Cu(0), the amount of photoactive $\mathrm{Au}(0)$ NPs, although not large, is significantly higher than the $\mathrm{Cu}(0)$ content in G-HIS-Cu(0) and most of the NPs of $\mathrm{Au}(0)$ have SPR energies that fit the excitation energy of the semiconductor moiety G-HIS $(0.47) .^{50,51,53}$ These facts together with the possible interactions of the $\mathrm{C} \pi-\mathrm{d} \pi$ type of $\mathrm{G}$ with the
$\mathrm{Au}$ atoms of the NPs allow us to assume that the dipole energy associated to SPR of $\mathrm{Au}(0) \mathrm{NPs}$ is efficiently transferred to the semiconductor G-HIS(0.47) moiety. This enhances the stability of the electron-positive hole pairs created at the end, allowing the excited electrons to reduce $\mathrm{H}_{3} \mathrm{O}^{+}$at the GHIS surface, while the positive holes are reduced by the oxidation of the sacrificial agent, lactic acid, yielding $\mathrm{CO}_{2}$ and $\mathrm{H}_{2} \mathrm{O}$ as reaction products. These results point out that the design of graphene-metal NP composites/hybrids based on non-covalent functionalized graphene as a supporting platform could be a feasible alternative to the use of other graphene derivatives requiring undesirable time-consuming and structure-damaging treatments to be obtained.

\section{CONCLUSIONS}

Non-covalent functionalization of graphene, G, in water with the compound HIS through interactions of $\pi_{\text {pyrimidine }}-$ $\mathrm{C} \pi^{*}$ graphene type gives rise to the splitting of the valence band and conduction band of G. The energy of the generated band gap can be finely tuned by controlling the amount of adsorbed HIS. The main advantages of this procedure over the graphene oxidation to obtain graphene-based semiconductors are both the fact that this new procedure preserves the basic structure of pristine graphene and that experimental conditions needed for obtaining of G-HIS hybrids are very mild, which allows finetuning of the generated band gap. Still, further research on this topic with G-HIS and another analogous G-ligands while doing a comparative study of the conductivity of $G$ with that of GHIS hybrids would shed more light on the issue.

Preservation of the complexing properties to metal ions and atoms of the pendant histidine residue after adsorption of HIS on $\mathrm{G}$ allows the stabilization of $\mathrm{Cu}(\mathrm{II})$ ions and $\mathrm{Cu}(0)$ clusters and $\mathrm{Au}(0) \mathrm{NPs}$ deposited on the surface of G-HIS hybrids. Taking advantage of the above, we obtained two hybrid materials consisting of coupling of $\mathrm{Cu}(0)$ clusters and $\mathrm{Au}(0)$ NPs with the semiconductor G-HIS. The G-HIS-Au(0) hybrid shows photocatalytic activity in water reduction reactions under radiation similar to solar light. This has been attributed to an effective transference of the SPR of $\mathrm{Au}(0)$ to the semiconductor G-HIS moiety, which allows the stabilization of the electron-hole pairs generated under radiation at the end. In his turn, it also favors efficient water reduction on the $G$ surface in the presence of lactic acid for the reduction of the positive holes. These primary results encourage deeper research work to improve the photocatalytic performances of this class of functionalized G-based materials through exploring (i) the influence of an increased amount of deposited 
semiconductor NPs including more inexpensive metals and metal compounds with semiconducting properties ( $\mathrm{CdS}$ and $\mathrm{BiXO}, \mathrm{X}=\mathrm{Cl}, \mathrm{Br}, \mathrm{I}$ ), (ii) the influence of the nature of the used NPs (e.g., crystallinity and sizes), and (iii) the extending research of pyrimidine derivatives analogous to HIS bearing other pendant complexing functions.

\section{EXPERIMENTAL SECTION}

Materials. Commercial graphene, G (2191YJ), from NanoAmor (U.S.A.) has been used. According to the manufacturer, the product has a carbon content of $>96 \mathrm{wt}$ $\%$, a size between 2 and $10 \mu \mathrm{m}$, and $1-3$ layers. It was washed with double-distilled water before using to remove small amounts of sulfur $\left(0.2\right.$ at. \%). ${ }^{54}$ All the solvents and the other chemicals were of analytical grade, used without any further purification, and purchased from commercial sources and used as supplied.

Synthesis and Characterization of HIS. HIS, 2-amino4,6-di-L-histidino-5-nitrosopyrimidine (Scheme 1b), was obtained as follows: in a first step, we obtained the compound 2amino-4,6-dimethoxy-5-nitrosopyrimidine (I). This was done by adding $5.16 \mathrm{~mL}$ of amyl nitrite to a solution of $5 \mathrm{~g}$ of 2amino-4,6-dimethoxypyrimidine in $20 \mathrm{~mL}$ of DMSO. The mixture was left reacting to dry for $24 \mathrm{~h}$ up to the formation of a purple blue gel. After cooling the gel into an ice bath, $200 \mathrm{~mL}$ of distilled water was added, which gave rise to the formation of a sky blue solid (I). This was filtered off and further washed with distilled water and then with a little amount of EtOH (yield, $3.87 \mathrm{~g}, 77 \%$ weight).

In the second step, the HIS compound was obtained as follows: to a solution of $0.50 \mathrm{~g}(2.7 \mathrm{mmol})$ of compound $\mathrm{I}$ in $12 \mathrm{~mL}$ of EtOH, $0.97 \mathrm{~g}(6.2 \mathrm{mmol})$ of L-histidine and $0.72 \mathrm{~g}$ $(5.9 \mathrm{mmol})$ of potassium terc-butoxide were added. The mixture was heated under reflux for $30 \mathrm{~h}$ at room temperature. Then, $\mathrm{HCl}(0.5 \mathrm{~mL}, 37 \%)$ was added until the molar $\mathrm{HCl} /$ potassium terc-butoxide relationship was $1.1 / 1$; after which, a reddish brown solid was precipitated. The solid was filtered off and washed with cold $\mathrm{MeOH}$ for several times. The solid was recrystallized in a $\mathrm{EtOH} / \mathrm{H}_{2} \mathrm{O}$ mixture (2/2.4 molar relationship), and the purified final solid was dried under vacuum at 80 ${ }^{\circ} \mathrm{C}$ for 24 hours (yield, $0.46 \mathrm{~g}$, 91\% weight).

The element composition of the synthesized compound was obtained with Thermo Finnigan Flash EA 1112 series equipment and ${ }^{13} \mathrm{C}$ and ${ }^{1} \mathrm{H}$ NMR spectra with a Bruker Avance 400 equipment.

Elemental analysis calculated for HIS. $3 \mathrm{H}_{2} \mathrm{O}\left(\mathrm{C}_{16} \mathrm{H}_{24} \mathrm{~N}_{10} \mathrm{O}_{8}\right)$ : C $39.67 \%$, N 28.91\%, H 4.99\%; found: C $39.69 \%$, N 29.15\%, $\mathrm{H} 4.70 \%$. Lateral histidine arms A and B produced two distinct set of signals due to the different chemical environments as a result of the strong intramolecular $\mathrm{H}$ bond $[5 \mathrm{~N}=\mathrm{O}-\mathrm{H}-\mathrm{N}$ (His)] that involves only one of the histidine moieties. ${ }^{1} \mathrm{H}$ RMN data (400 MHz DMSO- $\left.d_{6}\right) \delta(\mathrm{ppm}): 11.56(\mathrm{~d}, J=7.9$ $\mathrm{Hz}, 1 \mathrm{H})(\mathrm{A}), 8.55$ (d, $J=8.1 \mathrm{~Hz}, 1 \mathrm{H})(\mathrm{B}), 7.58$ (d, $J=1.0 \mathrm{~Hz}$, 1H) (B), 7.57 (d, J = $1.0 \mathrm{~Hz}, 1 \mathrm{H})(\mathrm{A}), 7.19$ (brs, $2 \mathrm{H}), 6.85$ (d, $J=1.0 \mathrm{~Hz}, 1 \mathrm{H})(\mathrm{B}), 6.93$ (brs, $4 \mathrm{H}), 6.82(\mathrm{~d}, J=1.0 \mathrm{~Hz}, 1 \mathrm{H})$ (A), 5.01 (ddd, $J=8.1,6.2,5.4 \mathrm{~Hz}, 1 \mathrm{H}$ ) (B), 4.92 (ddd, $J=$ $7.9,6.0,5.0 \mathrm{~Hz}, 1 \mathrm{H})(\mathrm{A}), 3.21(\mathrm{dd}, J=14.9,6.2 \mathrm{~Hz}, 1 \mathrm{H})(\mathrm{B})$, $3.16(\mathrm{dd}, J=14.9,5.4 \mathrm{~Hz}, 1 \mathrm{H})(\mathrm{B}), 3.10(\mathrm{dd}, J=14.7,5.0 \mathrm{~Hz}$, $1 \mathrm{H})(\mathrm{A}), 3.05(\mathrm{dd}, J=14.7,6.0 \mathrm{~Hz}, 1 \mathrm{H})(\mathrm{A}) .{ }^{13} \mathrm{C}$ NMR data $\left(101 \mathrm{MHz}, \mathrm{DMSO}-d_{6}\right) \delta(\mathrm{ppm}): 171.9$ (A), 171.4 (B), 163.7, 162.7, 149.1, 136.0, 134.3 (B), 134.2 (A), 133.4 (B), 132.5 (A), 116.0 (A), 115.6 (B), 52.60 (B), 51.90 (A), 28.9 (A), 28.6 (B).
Adsorption-Desorption Study of HIS on G. The adsorption isotherm of HIS in water (Figure S1) was obtained at $298.1 \mathrm{~K}$ and $\mathrm{pH}=5.0$. At these conditions, $100 \%$ of HIS is in a neutral molecular form (see Figure S2). The isotherm data were obtained by suspending $0.0100 \mathrm{~g}$ of $\mathrm{G}$ in $20 \mathrm{~mL}$ of the appropriate solution of HIS. The HIS concentration ranged from $3.4 \times 10^{-5}$ to $1.4 \times 10^{-3} \mathrm{M}$. The suspensions were continuously shaken in a thermostatic air incubator until the equilibrium was reached $(24 \mathrm{~h})$. The equilibrium concentrations were then obtained by measuring the UV absorbance at $290 \mathrm{~nm}$ (which corresponds to one of the isosbestic points of HIS) using a PerkinElmer Lambda 25 spectrophotometer. The desorption isotherm of HIS from the G-HIS hybrids at $\mathrm{pH}$ $=5.0$ (Figure S1) was also obtained point-by-point by recovering, drying, weighting, and re-suspending the solids (1 $\mathrm{mg}$ of material $/ 2 \mathrm{~mL}$ of water) from the adsorption isotherm. The equilibrium desorption was $24 \mathrm{~h}$, and the final concentrations were determined as for the adsorption isotherms.

Potentiometric Measurements. Potentiometric ( $\mathrm{pH}-$ metric) titrations were used to determine the protonation constants of HIS and those of the formation of the HIS$\mathrm{Cu}(\mathrm{II})$ complexes in water solutions using a procedure already reported. $^{55}$ The concentration of HIS was $1 \times 10^{-3} \mathrm{M}$ in all experiments. The $\mathrm{pH}$ range was 2.0-10.5. The titrations were performed in $0.1 \mathrm{M} \mathrm{Me}_{4} \mathrm{NCl}$ at $298.1 \pm 0.1 \mathrm{~K}$. A HIS $/ \mathrm{CuCl}_{2}=$ $1 / 1$ molar ratio was used to determine the equilibrium constants of the HIS- $\mathrm{Cu}$ (II) formed complexes. All the data were analyzed by using HYPERQUAD software, ${ }^{56}$ which allowed obtaining the protonation constants of HIS and the complexing constants of HIS to $\mathrm{Cu}(\mathrm{II})$. These appear in Tables S1 and S2 together with the corresponding species distribution plots in Figures S2 and S3, respectively.

Preparation of the G-HIS Hybrids. The preparation of G-HIS hybrid materials required the previous synthesis and characterization of HIS. This molecule was selected because it has a pyrimidine derivative able to attach to $G$ by a $\pi-\pi$ interaction and also has two histidine residues (Scheme $1 \mathrm{~b}$ ), which can behave as ligands. The acid-base properties of HIS and the complexation behavior to $\mathrm{Cu}$ (II) in aqueous solution were studied following a previously described method. ${ }^{56}$ The adsorption-desorption isotherms of HIS on G were studied as a previous step to obtain G-HIS hybrid materials (Figure S1). On the basis of this study, we have obtained four G-HIS hybrids labeled as G-HIS(0.47), G-HIS(0.27), G-HIS(0.17), and G-HIS(0.07), containing 0.47, 0.27, 0.17, and $0.07 \mathrm{mmol}$ of HIS per gram of G, respectively. These materials have been prepared with the following methodology from a suspension of $\mathrm{G}(0.0100 \mathrm{~g})$ on aqueous solutions of HIS $(20 \mathrm{~mL})$ at $\mathrm{pH} 5.0$ (the $\mathrm{pH}$ value at which the neutral HIS species is the major component, Figure S2). The HIS concentration used a range from $1.4 \times 10^{-3} \mathrm{M}$ to $7.5 \times 10^{-4} \mathrm{M}$. The suspension was shaken at $298.1 \mathrm{~K}$ in a thermostated air-incubator for $24 \mathrm{~h}$. Then, the solid was separated by filtration, washed with water, and dried in a desiccator with silica gel.

Preparation of the G-HIS-Metal Hybrids. G-HIS(0.47) hybrid was used to capture $\mathrm{Cu}(\mathrm{II})$ by complexation. Thus, a GHIS (0.47)-Cu(II) solid containing $0.51 \mathrm{mmol}$ of $\mathrm{Cu}(\mathrm{II})$ per gram of adsorbent was obtained by suspending G-HIS $(0.47)$ $(0.0100 \mathrm{~g})$ in a $4 \times 10^{-4} \mathrm{M}$ aqueous solution of $\mathrm{CuCl}_{2}(20$ $\mathrm{mL}$ ) at $\mathrm{pH} 5.0$ following the same procedure described for the preparation of G-HIS hybrids. The $\mathrm{Cu}$ (II) concentration was measured by atomic absorption spectrometry by using 
PerkinElmer Analyst 800 equipment. The experimental conditions used for the preparation of G-HIS-Cu(II) ( $\mathrm{pH}$ and ratio $\mathrm{G} / \mathrm{Cu}(\mathrm{II})$ ) were selected from the species distribution diagram of the system $\mathrm{HIS} / \mathrm{Cu}$ (II) (Figure S3). In addition, the adsorption isotherm of $\mathrm{Cu}(\mathrm{II})$ on $\mathrm{G}$ HIS(0.47) is collected in Figure S4.

The G-HIS-Cu(II) solid obtained was treated with hydrogen cold plasma ${ }^{57}$ in order to obtain $\mathrm{Cu}(0)$ nanoparticles supported on $\mathrm{G}$ by using a plasma generator device (Junior Advanced SP) from Europlasma. The employed equipment produces plasma by using a $2.45 \mathrm{GHz}$ microwave source. The sample, once in the device chamber, was outgassed to a residual pressure of $50 \mathrm{mT}$ Torr before the treatment. Prior to the treatment, hydrogen was flowed during $5 \mathrm{~min}(15 \mathrm{~mL}$. $\mathrm{min}^{-1}$ ) up to a stable pressure of $\sim 400 \mathrm{mTorr}$. The source power was set to $700 \mathrm{~W}$, and the time of treatment was $5 \mathrm{~min}$.

A G-HIS-Au(0) solid, containing $2.28 \mathrm{mmol}$ of $\mathrm{Au}(0)$ per gram, was obtained by dispersing with constant stirring of 10 $\mathrm{mg}$ of G-HIS(0.47) in $20 \mathrm{~mL}$ of a $1.25 \times 10^{-3} \mathrm{M} \mathrm{HAuCl}_{4}$ water solution. The procedure was carried out at $\mathrm{pH} 4.0$ at room temperature for $48 \mathrm{~h}$, which induces the precipitation of $\mathrm{Au}(0)$. The solid was separated by filtration, washed repeatedly with water, and dried into a desiccator with silica gel. The amount of adsorbed $\mathrm{Au}(0)$ was calculated by measuring the $\mathrm{Au}$ (III) concentration of the filtrated solution using Agilent ICP-MS 7900 equipment.

Surface Charge Density of G and G-HIS(0.47). The surface charge density ( $Q$ in $\mathrm{mmol} \mathrm{H}^{+} / \mathrm{g}$ of adsorbent) of $\mathrm{G}$ and G-HIS (0.47) was determined from the potentiometric titration of the solids ${ }^{31,32}$ in a water suspension at $298.1 \mathrm{~K}$ by following a previously described procedure ${ }^{15}$ using $\left(\mathrm{CH}_{3}\right)_{4} \mathrm{NOH}$ of $0.1 \mathrm{M}$ as a titrating agent. The proton isotherms are obtained by plotting $Q$ versus equilibrium $\mathrm{pH}$ values.

Spectrophotometric Measurements. The UV-visible absorption spectra (200 to $900 \mathrm{~nm}$ ) of water suspensions of G, G-HIS(0.47), G-HIS(0.27), G-HIS(0.17), G-HIS(0.07), and G-HIS- $\mathrm{Cu}(0)$ solids were recorded at room temperature by using $1 \mathrm{~cm}$ quartz cells on a PerkinElmer, Lambda 25, spectrophotometer. The obtained data were used for calculations of the direct and indirect band gap transitions for every material. ${ }^{36}$

XPS Spectra. The XPS spectra of the solids were obtained in a Kratos Axis Ultra DLD spectrometer. Monochromatic Al/ $\mathrm{Mg} \mathrm{K} \alpha$ radiation from a twin anode in a constant analyzer energy mode with a pass energy of 160 and $20 \mathrm{eV}$ (for the survey and high-resolution spectra, respectively) was used. The $\mathrm{C} 1 \mathrm{~s}$ transition at $284.6 \mathrm{eV}$ was used as a reference to obtain the heteroatom binding energies. The accuracy of the binding energy (B.E.) values was $\pm 0.2 \mathrm{eV}$.

TEM Micrographs. TEM images of the samples have been obtained with JEOL Mod. JEM-1010 equipment.

Photocatalytic Tests. The photocatalytic hydrogen production experiments were performed in a $25 \mathrm{~mL}$ doublewalled flask, sealed with a silicone rubber septum at $295.1 \mathrm{~K}$ and atmospheric pressure. A solar simulator (ABET Technologies Model LS-150) equipped with a $150 \mathrm{~W}$ xenon arc lamp was used as a visible light source to trigger the photocatalytic reaction under solar simulated conditions, according to the standard of 1.5 air mass, AM1.5G (as defined in ASTM, G173-03 standard). In each experiment, the catalyst ( $2 \mathrm{mg}$ ) was dispersed with constant stirring in a $5 \mathrm{~mL}$ mixed solution of lactic acid $(0.75 \mathrm{~mL})$ and water $(4.25 \mathrm{~mL})$. Prior to irradiation, the system was bubbled with argon for $10 \mathrm{~min}$ to remove the dissolved oxygen. After $22 \mathrm{~h}$, a $0.1 \mathrm{~mL}$ of the generated gas was collected through the septum, and the hydrogen content was analyzed by gas chromatography (GCAgilent Technologies 7820A, TCD, Ar carrier $5 \AA$ molecular sieve column).

\section{ASSOCIATED CONTENT}

\section{SI Supporting Information}

The Supporting Information is available free of charge at https://pubs.acs.org/doi/10.1021/acsomega.0c02006.

Contents: adsorption and desorption isotherms of HIS on $\mathrm{G}$, distribution diagrams for HIS protonation, $\mathrm{Cu}$ (II) complexation with HIS and tables of stability constants, adsorption isotherm of $\mathrm{Cu}(\mathrm{II})$ on G-HIS; nitrogen adsorption-desorption isotherms of $\mathrm{G}$ and G-HIS, determination of $\mathrm{G}$ and G-HIS proton isotherms, proton isotherms and distribution of acid groups in G and in G(HIS), UV absorption spectra of HIS, plot of the indirect energy transitions for G, G-HIS hybrids, and GHis- $\mathrm{Cu}(0)$, and HRTEM image of pristine graphene (PDF)

\section{AUTHOR INFORMATION}

\section{Corresponding Author}

Paloma Arranz-Mascarós - Department of Inorganic and Organic Chemistry, Faculty of Experimental Sciences, Jaen University, 23071 Jáen, Spain; 이이이.org/0000-0002-36935997; Email: parranz@ujaen.es

\section{Authors}

Maria Luz Godino-Salido - Department of Inorganic and Organic Chemistry, Faculty of Experimental Sciences, Jaen University, 23071 Jáen, Spain; 이이.org/0000-0003-32574431

Rafael López-Garzón - Department of Inorganic and Organic Chemistry, Faculty of Experimental Sciences, Jaén University, 23071 Jáen, Spain; 이이.org/0000-0001-7176-1913

Celeste García-Gallarín - Department of Inorganic and Organic Chemistry, Faculty of Experimental Sciences, Jaén University, 23071 Jáen, Spain; O orcid.org/0000-0001-84559837

Ignacio Chamorro-Mena - Department of Inorganic and Organic Chemistry, Faculty of Experimental Sciences, Jaén University, 23071 Jáen, Spain; (1) orcid.org/0000-0002-40847420

F. Javier López-Garzón - Department of Inorganic Chemistry, Faculty of Sciences, Granada University, 18071 Granada, Spain; 으이. orcid.org/0000-0003-4481-4578

Esperanza Fernández-García - Department of Inorganic and Organic Chemistry, Faculty of Experimental Sciences, Jaén University, 23071 Jáen, Spain; ○ orcid.org/0000-0001-97853349

María Dolores Gutiérrez-Valero - Department of Inorganic and Organic Chemistry, Faculty of Experimental Sciences, Jaén University, 23071 Jaén, Spain; 이이.org/0000-0002-74600143

Complete contact information is available at:

https://pubs.acs.org/10.1021/acsomega.0c02006

\section{Notes}

The authors declare no competing financial interest. 


\section{ACKNOWLEDGMENTS}

Support from the Spanish Government (project no. RTI2018101558-B-C21), Autonomous Regional Government (Junta de Andalucia, group nos. PAIDI FQM273 and RMN342), and University of Jaen (no. EI_FQM6-2019) is gratefully acknowledged. Technical and human support provided by SCAI of the University of Jaen (UJA, MINECO, Junta de Andalucia, and FEDER) is also acknowledged.

\section{REFERENCES}

(1) Craciun, M. F.; Khrapach, I.; Barnes, M. D.; Russo, S. Properties and applications of chemically functionalized graphene. J. Phys.: Condens. Matter 2013, 25, 423201-423223.

(2) Novoselov, K. S.; Geim, A. K.; Morozov, S. V.; Jiang, D.; Zhang, Y.; Dubonos, S. V.; Grigorieva, I. V.; Firsov, A. A. Electric Field Effect in Atomically Thin Carbon Films. Science 2004, 306, 666-669.

(3) Zhang, Y.; Tan, Y.-W.; Stormer, H. L.; Kim, P. Experimental observation of the quantum Hall effect and Berry's phase in graphene. Nature 2005, 438, 201-204.

(4) Geim, A. K. Graphene: Status and Prospects. Science 2009, 324, $1530-1534$.

(5) Ren, M.; Zhang, J.; Fan, M.; Ajayan, P. M.; Tour, J. M. LiBreathing Air Batteries Catalyzed by $\mathrm{MnNiFe} /$ Laser-Induced Graphene Catalysts. Adv. Mater. Interfaces 2019, 6, 19010351901044.

(6) Peng, T.; Li, K.; Zeng, P.; Zhang, Q.; Zhang, X. Enhanced Photocatalytic Hydrogen Production over Graphene Oxide-Cadmium Sulfide Nanocomposite under Visible Light Irradiation. J. Phys. Chem. C 2012, 116, 22720-22726.

(7) Low, J.; Yu, J.; Ho, W. Graphene-based photocatalysts for $\mathrm{CO}_{2}$ reduction to solar fuel. J. Phys. Chem. Lett. 2015, 6, 4244-4251.

(8) Leon y Leon, C. A.; Solar, J. M.; Calemma, V.; Radovic, L. R. Evidence for the protonation of basal plane sites on carbon. Carbon 1992, 30, 797-811.

(9) Pei, S.; Cheng, H.-M. The Reduction of Graphene Oxide. Carbon 2012, 50, 3210-3228.

(10) Shown, I.; Hsu, H.-C.; Chang, Y.-C.; Lin, C.-H.; Roy, P. K.; Ganguly, A.; Wang, C.-H.; Chang, J.-K.; Wu, C.-I.; Chen, L.-C.; Chen, K.-H. Highly efficient visible light photocatalytic reduction of $\mathrm{CO}_{2}$ to hydrocarbon fuels by $\mathrm{Cu}$-nanoparticle decorated graphene oxide. Nano Lett. 2014, 14, 6097-6103.

(11) Eda, G.; Lin, Y.-Y.; Mattevi, C.; Yamaguchi, H.; Chen, H.-A.; Chen, I.-S.; Chen, C.-H.; Chhowalla, M. Blue photoluminescence from chemically derived graphene oxide. Adv. Mater. 2010, 22, 505509.

(12) Jung, I.; Dikin, D. A.; Piner, R. D.; Ruoff, R. D. Tunable Electrical Conductivity of Individual Graphene Oxide Sheets Reduced at "Low" Temperatures. Nano Lett. 2008, 8, 4283-4287.

(13) García-Martín, J.; López-Garzón, R.; Godino-Salido, M. L.; Gutiérrez-Valero, M. D.; Arranz-Mascarós, P.; Cuesta, R.; CarrascoMarín, F. Ligand Adsorption on an Activated Carbon for the Removal of Chromate Ions from Aqueous Solutions. Langmuir 2005, 21, 6908-6914.

(14) Gutiérrez-Valero, M. D.; Godino-Salido, M. L.; ArranzMascarós, P.; López-Garzón, R.; Cuesta, R.; García-Martín, J. Adsorption of Designed Pyrimidine Derivative Ligands on an Activated Carbon for the Removal of $\mathrm{Cu}$ (II) Ions from Aqueous Solution. Langmuir 2007, 23, 5995-6003.

(15) Arranz, P.; Bianchi, A.; Cuesta, R.; Giorgi, C.; Godino, M. L.; Gutiérrez, M. D.; López, R.; Santiago, A. Binding and Removal of Sulfate, Phosphate, Arsenate, Tetrachloromercurate, and Chromate in Aqueous Solution by Means of an Activated Carbon Functionalized with a Pyrimidine-Based Anion Receptor (HL). Crystal Structures of $\left[\mathrm{H}_{3} \mathrm{~L}\left(\mathrm{HgCl}_{4}\right)\right] \cdot \mathrm{H}_{2} \mathrm{O}$ and $\left[\mathrm{H}_{3} \mathrm{~L}\left(\mathrm{HgBr}_{4}\right)\right] \cdot \mathrm{H}_{2} \mathrm{O}$ Showing Anion- $\pi$ Interactions. Inorg. Chem. 2010, 49, 9321-9332.

(16) García-Martín, J.; López-Garzón, R.; Godino-Salido, M. L.; Cuesta-Martos, R.; Gutiérrez-Valero, M. D.; Arranz-Mascarós, P.; Stoeckli-Evans, $\mathrm{H}$. Adsorption of $\mathrm{Zn}^{2+}$ and $\mathrm{Cd}^{2+}$ from Aqueous
Solution onto a Carbon Sorbent Containing a Pyrimidine-Polyamine Conjugate as Ion Receptor. Eur. J. Inorg. Chem. 2005, 3093-3103.

(17) López-Garzón, R.; Godino-Salido, M. L.; Gutiérrez-Valero, M. D.; Arranz-Mascarós, P.; Melguizo, M.; García, C.; Domingo-García, M.; López-Garzón, F. J. Supramolecular assembling of molecular ionligands on graphite-based solid materials directed to specific binding of metal ions. Inorg. Chim. Acta 2014, 417, 208-221.

(18) Savastano, M.; Arranz-Mascarós, P.; Bazzicalupi, C.; Clares, M. P.; Godino-Salido, M. L.; Gutiérrez-Valero, M. D.; Inclán, M.; Bianchi, A.; García-España, E.; López-Garzón, R. Construction of green nanostructured heterogeneous catalysts via non-covalent surface decoration of multi-walled carbon nanotubes with $\mathrm{Pd}(\mathrm{II})$ complexes of azamacrocycles. J. Catal. 2017, 353, 239-249.

(19) Arranz-Mascarós, P.; Bazzicalupi, C.; Bianchi, A.; Giorgi, C.; Godino-Salido, M.-L.; Gutiérrez-Valero, M.-D.; López-Garzón, R.; Savastano, M. Thermodynamics of Anion- $\pi$ Interactions in Aqueous Solution. J. Am. Chem. Soc. 2013, 135, 102-105.

(20) Low, J. N.; López, M. D.; Arranz Mascarós, P.; Cobo Domingo, J.; Godino, M. L.; López Garzón, R.; Gutiérrez, M. D.; Melguizo, M.; Ferguson, G.; Glidewell, C. N-(6-Amino-3,4-dihydro-3-methyl-5nitroso-4-oxopyrimidin-2-yl) derivatives of glycine, valine, serine, threonine and methionine: Interplay of molecular, molecularelectronic and supramolecular structures. Acta Crystallogr., Sect. B: Struct. Sci. 2000, 56, 882-892.

(21) Arranz Mascarós, P.; Gutiérrez Valero, M. D.; Low, J. N.; Glidewell, C. N-(3-Methyl-4-oxo-3,4-dihydropteridin-2-yl)glycine: hydrogen-bonded sheets of $\mathrm{R}_{4}{ }^{4}(22)$ and $\mathrm{R}_{4}{ }^{4}$ (30) rings. Acta Crystallogr. C 2004, 60, o795-o797.

(22) Godino Salido, M. L.; Arranz Mascarós, P.; López Garzón, R.; Gutiérrez Valero, M. D.; Low, J. N.; Gallagher, J. F.; Glidewell, C. Hydrated metal(II) complexes of N-(6-amino-3,4-dihydro-3-methyl5-nitroso-4-oxopyrimidin-2-yl) derivatives of glycine, glycylglycine, threonine, serine, valine and methionine: a monomeric complex and coordination polymers in one, two and three dimensions linked by hydrogen bonding. Acta Crystallogr., Sect. B: Struct. Sci. 2004, 60, 4664.

(23) Savastano, M.; Arranz-Mascarós, P.; Bazzicalupi, C.; Bianchi, A.; Giorgi, C.; Godino-Salido, M. L.; Gutiérrez-Valero, M. D.; LópezGarzón, R. Binding and removal of octahedral, tetrahedral, square planar and linear anions in water by means of activated carbon functionalized with a pyrimidine-based anion receptor. RSC $A d v$. 2014, 4, 58505-58513.

(24) Savastano, M.; Arranz-Mascarós, P.; Bazzicalupi, C.; Clares, M. P.; Godino-Salido, M. L.; Guijarro, L.; Gutiérrez-Valero, M. D.; Bianchi, A.; Garcia-España, E.; López-Garzón, R. Polyfunctional Tetraaza-Macrocyclic Ligands: $\mathrm{Zn}$ (II), Cu(II) Binding and Formation of Hybrid Materials with Multiwalled Carbon Nanotubes. ACS Omega 2017, 2, 3868-3877.

(25) Savastano, M.; Arranz-Mascarós, P.; Clares, M. P.; Cuesta, R.; Godino-Salido, M. L.; Guijarro, L.; Gutiérrez-Valero, M. D.; Inclán, M.; Bianchi, A.; García-España, E.; López-Garzón, R. A New Heterogeneous Catalyst Obtained via Supramolecular Decoration of Graphene with a $\mathrm{Pd}^{2+}$ Azamacrocyclic Complex. Molecules 2019, 24, 2714.

(26) Incze, A.; Pasturel, P.; Chatillon, C. Oxidation of graphite by atomic oxygen: a first-principles approach. Surf. Sci. 2003, 537, 5563.

(27) Lerf, A.; He, H.; Forster, M.; Klinowski, J. Structure of Graphite Oxide Revisited. J. Phys. Chem. B 1998, 102, 4477-4482.

(28) Abdelkader-Fernández, V. K.; Domingo-García, M.; LópezGarzón, F. J.; Fernades, D. M.; Freire, C.; de la Torre, M. D. L.; Melguizo, M.; Godino-Salido, M. L.; Pérez-Mendoza, M. Expanding graphene properties by a simple S-doping methodology based on cold $\mathrm{CS}_{2}$ plasma. Carbon 2019, 144, 269-279.

(29) King, A. A. K.; Davies, B. R.; Noorbehesht, N.; Newman, P.; Church, T. L.; Harris, A. T.; Razal, J. M.; Minett, A. I. A New Raman Metric for the Characterisation of Graphene oxide and its Derivatives. Sci. Rep. 2016, 6, 19491. 
(30) Giles, C. H.; MacEwan, T. H.; Nakhwa, S. N.; Smith, D. Studies in Adsorption. Part XI. A System of Classification of Solution Adsorption Isotherms, and its Use in Diagnosis of Adsorption Mechanisms and in Measurement of Specific Surface Areas of Solids. J. Chem. Soc. 1960, 111, 3973-3993.

(31) Bandosz, T. J.; Jagiello, J.; Contescu, C.; Schwarz, J. A. Characterization of the surfaces of activated carbons in terms of their acidity constant distributions. Carbon 1993, 31, 1193-1202.

(32) Jagiełło, J.; Bandosz, T. J.; Schwarz, J. A. Carbon surface characterization in terms of its acidity constant distribution. Carbon 1994, 32, 1026-1028.

(33) Lai, Q.; Zhu, S.; Luo, X.; Zou, M.; Huang, S. Ultraviolet-Visible Spectroscopy of Graphene Oxides. AIP Adv. 2012, 2, No. 032146.

(34) Luo, Z.; Lu, Y.; Somers, L. A.; Johnson, A. T. C. High Yield Preparation of Macroscopic Graphene Oxide Membranes. J. Am. Chem. Soc. 2009, 131, 898-899.

(35) Kaciulis, S.; Mezzi, A.; Calvani, P.; Trucchi, D. M. Electron spectroscopy of the main allotropes of carbon. Surf. Interface Anal. 2014, 46, 966-969.

(36) Yeh, T.-F.; Syu, J.-M.; Cheng, C.; Chang, T.-H.; Teng, H. Graphite Oxide as a Photocatalyst for Hydrogen Production from Water. Adv. Funct. Mater. 2010, 20, 2255-2262.

(37) Morales, A. E.; Mora, E. S.; Pal, U. Use of diffuse reflectance spectroscopy for optical characterization of un-supported nanostructures. Rev. Mex. Fis. 2007, 53, 18-22.

(38) Putri, L. K.; Ng, B.-J.; Tan, K. H.; Lim, F. S.; Ong, W.-J.; Chang, W. S.; Chai, S.-P. Tailoring the properties of oxygenated graphene with different oxidation degrees for noble-metal-free photocatalytic hydrogen evolution. Catal. Today 2018, 315, 93-102.

(39) Arranz-Mascarós, P.; Bazzicalupi, C.; Bianchi, A.; Giorgi, C.; Gutiérrez-Valero, M. D.; López-Garzón, R.; Godino-Salido, M. L.; Valtancoli, B. Molecular recognition of ADP over ATP in aqueous solution by polyammonium receptor containing a pyrimidine residue. Chem. Commun. 2011, 47, 2814-2816.

(40) Moniz, S. J. A.; Shevlin, S. A.; Martin, D. J.; Guob, Z.-X.; Tang, $\mathrm{J}$. Visible-light driven heterojunction photocatalysts for water splitting - a critical review. Energy Environ. Sci. 2015, 8, 731-759.

(41) Rawner, T.; Lutsker, E.; Kaiser, C. A.; Reiser, O. The Different Faces of Photoredox Catalysts: Visible-Light-Mediated Atom Transfer Radical Addition (ATRA) Reactions of Perfluoroalkyl Iodides with Styrenes and Phenylacetylenes. ACS Catal. 2018, 8, 3950-3956.

(42) Gutiérrez-Valero, M. D.; Arranz-Mascarós, P.; Godino-Salido, M. L.; López-León, M. D.; López-Garzón, R.; Cuesta, R. Adsorption of a designed L-glutamic acid-pyrimidine derivative ligand on an activated carbon for the removal of $\mathrm{Cu}$ (II) from aqueous solution. Microporous Mesoporous Mater. 2008, 116, 445-451.

(43) Derylo-Marczewska, A.; Swiatkowski, A.; Biniak, S.; Walczyk, M. Effect of properties of chemically modified activated carbon and aromatic adsorbate molecule on adsorption from liquid phase. Colloids Surf., A 2008, 327, 1-8.

(44) NIST X-ray photoelectron spectroscopy database, Measurement Services Division of the National Institute of Standards and Technology (NIST) Technology Services, 2008.

(45) Abdelkader-Fernández, V. K.; Morales-Lara, F.; de la Torre, M. D. L.; Melguizo, M.; López-Garzón, F. J.; Domingo-García, M.; PérezMendoza, M. HBPEI-grafted carbon nanotubes for the effective retention of $\mathrm{Pd}^{2+}$ and $\mathrm{Pt}^{2+}$ through complexation. Inorg. Chem. Front. 2018, 5, 1978-1984.

(46) Balogh, L.; Tomalia, D. A. Poly(Amidoamine) DendrimerTemplated Nanocomposites. 1. Synthesis of Zerovalent Copper Nanocluster. J. Am. Chem. Soc. 1998, 120, 7355-7356.

(47) Gurin, V. S.; Petranovskii, V. P.; Pestryakov, A. N.; Kryazhov, A.; Ozhereliev, O.; Hernandes, M.-A.; Alexeenko, A. A. Copper clusters and small particles stabilized within nanoporous materials. Eur. Phys. J. D 2003, 24, 381-384.

(48) Lisiecki, I.; Pileni, M. P. Copper Metallic Particles Synthesized "in Situ" in Reverse Micelles: Influence of Various Parameters on the Size of the Particles. J. Phys. Chem. 1995, 99, 5077-5082.
(49) Zhang, P.; Song, T.; Wang, T.; Zeng, H. Plasmonic Cu nanoparticle on reduced graphene oxide nanosheet support: An efficient photocatalyst for improvement of near-infrared photocatalytic $\mathrm{H}_{2}$ evolution. Appl. Catal., B 2018, 225, 172-179.

(50) Yeh, Y.-C.; Creran, B.; Rotello, V. M. Gold Nanoparticles: Preparation, Properties, and Applications in Bionanotechnology. Nanoscale 2012, 4, 1871-1880.

(51) Jain, P. K.; Lee, K. S.; El-Sayed, I. H.; El-Sayed, M. A Calculated absorption and scattering properties of gold nanoparticles of different size, shape, and composition: applications in biological imaging and biomedicine. J. Phys. Chem. B 2006, 110, 7238-7248.

(52) De Souza, M. L.; Dos Santos, D. P.; Corio, P. Localized surface plasmon resonance enhanced photocatalysis: an experimental and theoretical mechanistic investigation. RSC Adv. 2018, 8, 2875328762.

(53) Templeton, A. C.; Pietron, J. J.; Murray, R. W.; Mulvaney, P. Solvent Refractive Index and Core Charge Influences on the Surface Plasmon Absorbance of Alkanethiolate Monolayer-Protected Gold Clusters. J. Phys. Chem. B 2000, 104, 564-570.

(54) Abdelkader-Fernández, V.; Melguizo, M.; Domingo-García, M.; López-Garzón, F. J.; Pérez-Mendoza, M. Hydrogen cold plasma for the effective reduction of graphene oxide. Appl. Surf. Sci. 2019, 464, 673-681.

(55) Godino-Salido, M. L.; Gutiérrez-Valero, M. D.; López-Garzón, R.; Moreno-Sánchez, J. M. Zn(II) complexes with thiopyrimidine derivatives: solution study, synthesis and crystal structure of a zig-zag chain zinc(II) complex with the ligand 4,6-dimethyl-2-thiopyrimidine. Inorg. Chim. Acta 1994, 221, 177-181.

(56) Gans, P.; Sabatini, A.; Vacca, A. Investigation of equilibria in solution. Determination of equilibrium constants with the HYPERQUAD suite of programs. Talanta 1996, 43, 1739-1753.

(57) Linares, F.; García-Fernández, E.; López-Garzón, F. J.; Domingo-García, M.; Orte, A.; Rodríguez-Diéguez, A.; Galindo, M. A. Multifunctional behaviour of molecules comprising stacked cytosine- $\mathrm{Ag}^{\mathrm{I}}-$ cytosine base pairs; towards conducting and photoluminescence silver-DNA nanowires. Chem. Sci. 2019, 10, 11261137. 